Article

\title{
"We Are Prisoners in Our Own Homes": Connecting the Environment, Gender-Based Violence and Sexual and Reproductive Health Rights to Sport for Development and Peace in Nicaragua
}

\author{
Lyndsay M. C. Hayhurst ${ }^{1, *}$ and Lidieth del Socorro Cruz Centeno ${ }^{2}$ \\ 1 School of Kinesiology and Health Science, Faculty of Health, York University, 4700 Keele Street, \\ Toronto, ON M3J 1P3, Canada \\ 2 Independent Scholar, Rivas, Nicaragua \\ * Correspondence: lhayhurs@yorku.ca
}

Received: 9 July 2019; Accepted: 14 August 2019; Published: 19 August 2019

\begin{abstract}
This paper draws on postcolonial feminist political ecology theory, feminist theories of violence and new materialist approaches to sport and physical cultural studies—combined with literature on the role of non-humans in international development-to unpack the connections between gender-based violence and the environment in sport, gender and development (SGD) programming in Nicaragua. To do this, postcolonial feminist participatory action research (PFPAR), including visual research methods such as photovoice, was used to better understand, and prioritize, young Nicaraguan women's experiences of the environment and gender-based violence as they participated in an SGD program used to promote environmentalism and improve their sexual and reproductive health rights. To conclude, the importance of accounting for the broader physical environment in social and political forces was underlined as it shapes the lives of those on the receiving end of SGD interventions.
\end{abstract}

Keywords: sport for development and peace; sport gender and development; environment; sustainability; gender-based violence; sexual and reproductive health; postcolonial feminist theory; political ecology; participatory action research

\section{Introduction}

"In the Nicaraguan climate change discourse, women end up bearing most responsibilities in the fight against climate change, thus making this gendering an oppressive process that constructs women with particular traits, considered as immutable." [1] (p. 175)

"According to the United Nations, one in three women is beaten or sexually abused in her lifetime. The math is simple: One billion women have or will experience gender-based violence." [2]

This study shares the excerpts above to draw attention to the ways that sport for development and peace (SDP) - or the use of sport to achieve development objectives as outlined by the United Nations Sustainable Development Goals-intersects with environmental degradation in Nicaragua, gender-based violence, sexual and reproductive health rights, and the activities pursued by non-governmental organizations (NGOs) as tenable solutions to address these same issues. Certainly, feminist political ecology perspectives on climate change posits that the relationship between the environment and gender is an active process largely shaped by culture and society, and it remains relatively novel within academic and policy arenas alike [3,4]. Similarly, the use of sport, gender, and development (SGD) programming is also understood as how sport is used to address gender-related (international) development goals and how it attends to (environmental) sustainability, gender-based 
violence, and sexual and reproductive health rights (SRHR) which remains understudied. Taken together, then, the purpose of this paper is to use empirical work from a study undertaken in Nicaragua to critically consider the nexus of climate change, gender-based violence (GBV) prevention, and sexual and reproductive health rights (SRHR) promotion within the broader field of sport for development and peace, and more specifically, vis-à-vis SGD programming.

To pursue this objective, this study explores the following four research questions: (1) How can we be more mindful of the manner in which climate change and sustainability practices become gendered, and more vigilant of the processes that reinforce (naturalized) gendered hierarchies; (2) What is the role of SGD in lessening, augmenting, and/or exacerbating environmental degradation and its related inequalities; (3) How might SGD be used to prevent GBV and violence to our environment? (4) What is the role of the physical environment in lessening, augmenting and upholding inequality in relation to gendered climate change politics and how might such politics impact GBV and SRHR-centered programming through SGD?

Our aim is to contribute to sociological, feminist and environmental studies of SDP in a number of ways. First, as Giulianotti et al. [5] contend, the time is ripe to better account for the broader physical environment in social and political life as it shapes the lives of those on the receiving ends of SDP interventions. Second, and by extension, we suggest that we must go beyond a sole focus on the broader physical environment to also consider the gendered dimensions of environmental issues. In particular, by thinking through the multitude of ways in which climate change impacts people not simply in diverse geographical contexts, but also "within the same locations due to differences in such factors as social roles, resources, and expectations," [4] (p. 682). Third, we argue that SGD programs-whether they discursively include environmental sustainability and climate change adaptation aspects or not-may inadvertently contribute to upholding patriarchy while also risk essentializing women's and girls' traditional gender roles, exacerbating gendered divisions of labour, and potentially reinforcing assumptions about "women's natural connection to nature" by positioning women as "especially apt to fight environmental degradation and climate change" [1] (p. 173). In turn, we suggest that there is a clear gap in the SDP literature (and practice) and a need to critically examine the ways in which the physical environment, specifically, in relation to climate change and pollution, enmeshes with, and impacts, SGD programming, particularly initiatives that are focused on GBV prevention and SRHR promotion for young women.

To pay heed to this call—we use postcolonial political feminist political ecology approaches [6,7] inspired and informed by feminist sociomaterialisms [8,9] and feminist conceptualizations of violence $[10,11]$, to critically consider work from a digital participatory action research study with a NGO based in rural Nicaragua that uses fútbol (soccer) to promote sexual and reproductive health rights, address gender-based violence and navigate the effects of environmental degradation in their community.

\section{Literature Review}

\subsection{Sport and the Environment}

In 2005, the UN Inter-Agency Task Force on SDP highlighted the auspicious connection between SDP and environmental sustainability, noting the "inherent link between a clean environment and participation in sport is part of what makes sport a powerful tool for communicating environmental messages and encouraging action to clean up the environment" [12] (p. 13). The UN is not the first international organization to put forth such connections. Indeed, since the early 1990s, various scholars have documented how international sporting organizations, such as the IOC and FIFA, continue to greenwash their work and host sporting events that damage the environment [13-16].

Other research focuses on how specific sporting industries pose detrimental environmental effects. For example, Stoddart [17] reflects on the ecological irony, or "the detachment between abstract values and embodied behaviour" (p. 20), evident in the ways that skiers in British Columbia negotiate their 
pro-environmental stances with environmentally harmful behaviour (i.e., the contribution of skiing to increased greenhouse gas emissions). Other studies focus on how sports, such as golf, damage the natural environment, particularly through its use of chemicals, to negatively impact forests and water waste (see [18-21]). In fact, Wilson and Millington [18] contend that ecological modernist discourses serve as the backbone to the majority of environmental promotionalism by sport-focused organizations and corporations. At times, such an approach tends to prioritize a capitalistic framework and neoliberal fortitude, whereby decisions related to pursuing sport-related activities uphold the economic and technological advances for addressing sport-related environmental challenges. Ecological modernists tend to embrace anthropocentric perspectives whereby the human elements of development projects are favoured over the non-human [21]. Taken together, what these studies demonstrate is a clear link between the pursuit of sport and economic interests, often at the expense of the physical environment. As Wilson [22] contends, we need to "continue to document and examine environmental politics in and around sport ... with the goal of exposing myths that hinder creative/inclusive thinking about pro-environment social and political action" (p. 104). This appeal to act is also applicable to SDP programming and practice as an example of a global social movement with an avowed motivation to create positive social, economic, and environmental legacies for communities targeted by development aid [23].

\subsubsection{SDP and The Environment: A Call for Feminist Approaches}

Although SDP-focused NGOs, such as Mathare Youth Sports Association (MYSA), have made environmental issues a cornerstone of their work since their inception in 1987, the broader SDP movement has mostly ignored the physical environment and its related components as essential to its mission of using sport as a tool for social development and change. Indeed, NGOs such as MYSA, which is an SDP NGO in Mathare, an informal settlement in Nairobi, Kenya that is home to approximately 500,000 people, use incentives embedded in their SDP programing to motivate participants to take the burden of pollution into their own hands:

Instead of having to pay fees to play soccer in MYSA, which they could hardly afford, Nairobi's poorest
slum children would do clean-up projects. Each successful completion of the approved clean-up project
would earn a team six points (equivalent to two wins) in league standings. While initially seeming
strange to the residents of Mathare, has now become commonplace, that is, on weekends and on
holidays, teams of youths are seen with hoes, shovels and wheelbarrows clearing garbage and digging
ditches. This remarkable initiative was recognized at the 1992 Earth Summit in Rio de Janeiro with a
UNEP Global 500 Award. [24] ( $p .832$ )

Apart from Willis' account of MYSA's work, other SDP-focused research considers the concept of sustainability in and through 'action sports', such as surfing. For example, Wheaton et al.'s work on surfing-based action SDP programs demonstrates how program participants may struggle to maintain long-term and independent "ecological sensibilities to the sea and surf" through such initiatives [25] (p. 12). Others contend that promoting environmentalism in or through sport for development is a key cornerstone of promoting peace, particularly when thinking of sport as a medium through which to address cultural and structural forms of violence (e.g., [22]), a point which is taken up in greater detail in the latter half of this paper.

Further studies discuss the links between SDP and the physical environment, environmental degradation, and threats posed by climate change (Giulionotti et al., 2018 [5]; Millington et al., 2016 [26]). However, these works tend to overlook the gendered aspects embedded in these matters. As Giulianotti et al. (2018 [5], p. 3) note in a recent article published in Sustainability, "there has been no detailed research or discussion on the physical environment within the academic literature on SDP." Specifically, they conclude that the time is ripe to better understand how and in what ways the SDP sector has overlooked key dimensions related to its burgeoning role in environmentalism (e.g., climate change, pollution, sustainability, etc.), while also illuminating a number of potential opportunities in terms of 
possible ways forward for researchers to study the intersections among SDP, sustainable development and environmentalism [5]. Here, it seems crucial to define sustainability and its utilization within the wider development context. The term sustainable development was catapulted into eminence during the 1987 UN-sponsored Brundtland Commission [27]. Hereafter, the idea of sustainability was broadly infused into academic discourses to:

Subvert the foundational linear-teleological undertones of modernisation [sic] or 'progress' and suggest a more enduring standard of living, the term has become so commonplace that it is now too vague to talk of 'sustainable development' without specific reference to the environment, although it can also refer to the social, economic and even political. [28] (p. 926)

For the most part, what seems to be notably absent from discussions of sustainable development are the nebulous and diverse characteristics of the targeted beneficiaries enveloped in environmental practices, particularly women and girls.

\subsubsection{Sport, Gender, Development and the Environment}

There has been a surge of research on gender-focused SDP, or SGD, in the last fifteen years (e.g., $[29,30])$. A number of studies in this area explore and question the positioning of girls as agents of social change vis-à-vis SGD interventions in relation to the Girl Effect, a campaign launched by the Nike Foundation in 2005 that situates girls (particularly in the global South) as agents of change and the new panaceas of development (e.g., [31]), or investigates the discourses that travel to different contexts through SGD, such as via the US State Department's Empowering Women and Girls Through Sports initiative [32]. Recently, a Special Issue of Sport in Society explored a myriad of young women's experiences in SDP as the subjects of HIV/AIDS prevention strategies [33,34], CSR campaigns [35], or as participants looking for sporting role models [36]. Other works in this series deliberate the role of the family in influencing young women's choices to participate in SGD interventions [37], or observe the utility of soccer in building confidence and negotiating gender(ed) identities [38].

Further topical publications in the SGD arena investigate action sports for gender and development (see $[39,40])$. Action sports for development campaigns advocate for a broader focus on the physical environment by suggesting that these sports connect more deeply to issues related to environmental sustainability than mainstream sports (see [25,41]). For example, Thorpe [39] demonstrates how NGOs, such as Surfers Environmental Alliance, Surfers Against Sewage, and Protect Our Winters, use snowboarding, skiing, and surfing to raise awareness about environmental deprivation, pollution, and climate change. However, what remains mostly absent from the literature is a better understanding of how the physical environments in which these individuals partake in such programs are relevant, and influential, for shaping their health, well-being and safety.

In fact, a number of current SGD programs explicitly address the health, well-being and safety of participants in order to empower young women and girls through curriculum anchored in sexual and reproductive health rights, gender-based violence prevention, and social entrepreneurship (e.g., [42]). Despite these efforts, the physical environments in which these programs take place inadvertently impact the ways these young women (purportedly) take up and retain knowledge about these same issues. As shown through the empirical work presented in this paper, a postcolonial feminist political ecology approach, when used in conjunction with feminist conceptualizations of violence and sociomaterialisms, draws attention to the ways that objects and actants disrupt and subvert the (stated) intentions of a given program.

\subsection{Connecting Gender-Based Violence, Sexual and Reproductive Health Rights, and Sport}

According to UN Women [43], nearly one in three women globally experience sexual or physical violence, most often from a domestic partner, while the World Health Organization [44] estimates that $36.1 \%$ of women in the Americas (including Nicaragua) report intimate partner violence and/or non-partner sexual violence, though absolute numbers tend to be capricious because of 
under-reporting [45]. Following the work of Simister [46], the term gender-based violence (GBV) is used throughout this paper to highlight the gendered nature described by other terms, such as intimate partner violence or domestic violence.

A caveat in taking up these terms is recognizing how the challenges of vernacularization shape such conceptual understandings. Vernacularization is the process through which global concepts and ideas that are thought to be homogenous end up being re-constituted in local contexts. For example, global understandings of gender-based violence, sexual and reproductive health rights, sustainability, and sport for development and peace are not always uniformly understood locally. As Merry [47] suggests, "what constitutes violence against women is highly contested, ranging from narrow definitions of rape and intimate partner violence to broad conceptions that include sexual slavery during wartime, female genital cutting, sex trafficking, child marriage, and violence while in police custody" (p. 44). Brackenridge et al. [48] concur, as they note in their study on violence against children in sport, "countries approach the matter of violence against children in many different ways (including child labour; prevention of sexual/economic exploitation; health promotion; cultural or educational development) so there is no common agreement on what constitutes adequate violence prevention" (p. 6).

One of the initial definitions of sexual and reproductive health is clearly implied in the Beijing Declaration and Platform for Action [49], as "a state of complete physical, mental and social well-being and not merely the absence of disease or infirmity, in all matters relating to the reproductive system and to its functions and processes" (p. 35). Thus, while SRHR might broadly encompass issues such as violence against women, it mostly focuses on health issues related to maternal health and mortality, the violations of rights, how to say no to risky sex, offering accessible health services for women and girls such as antenatal care, family planning, post-abortion care, HIV testing, sexuality education as well as providing mental health and addressing sexually transmitted infections [50]. Bobel [51] attributes the concept of reproductive justice as one formed in 1994 by twelve US women of color-part of the SisterSong Women of Color Reproductive Justice Collective-which they define as "the human right to maintain personal bodily autonomy, have children, not have children and parent the children we have in safe and sustainable communities," [52] (p. 287, italics added for emphasis). Here, the crucial connection to safe and sustainable communities is underlined, and clearly bespeaks the need to better understand how SRHR might hinge on environmental justice and sustainability practices vis-à-vis SGD programming.

Hereafter, SRHR firmly emerged on the global development agenda in 2007 when the UN finally recognized that achieving universal access to reproductive health by 2015 was a key area of realizing Goal 5, to improve maternal health [50]. While various international agencies and government bodies are beginning to acknowledge GBV and SRHR as intertwined, more often than not, GBV continues to be framed, passively referenced or embedded within larger discussions of SRHR. In particular, for the development industry, funding maternal health seems to be more appealing to donors than funding GBV prevention (see [11]). In a similar vein, sport-focused GBV prevention programs tend to be combined with SRHR promotion activities, as discussed further below.

Although sport-focused development programs that use or take up GBV and SRHR continue to proliferate, a few scholars have critically examined how such concepts are utilized, implemented, and/or understood by the participants, practitioners, and policy-makers. In the global North context, GBV, sexual and physical abuse have mostly been studied in relation to sport programming (and not SDP programming). In particular, a number of studies have focused on physical abuse [53], sexual abuse and harassment of women by athletes, coaches, and other expert figures in sport [54], as well as emotional and psychological abuse [55]. The research based in the global North explains how sport participation may expose female athletes to increased instances of sexual violence and harassment [56,57]). However, in contrast, the protection hypothesis suggests that sport is actually useful for females to build their capacity to protect and defend themselves against sexual harassment and abuse by developing self-esteem and physical strength [58]. 
The studies by scholars exploring gender in relation to sport and physical activity in Nicaragua have noted that women and girls who participate in sport, whether as audience members or athletes, may in fact experience more sexual harassment and violence through their involvement (particularly in public spaces), and thus experience greater stigmatization through their participation [59]. Consequently, there are a few spaces where young women and girls feel safe and comfortable enough to participate in physical activity and sport [60], particularly since many of them experience verbal and physical harassment when they do participate [61]. As a result, various NGOs and practitioners attempted to develop SGD programs that use combative sports, such as boxing and martial arts, in combination with SRHR education campaigns and GBV-prevention strategies in order to empower women and girls with the knowledge and skills to feel safe [62]. Similarly, researchers have examined how self-defence sports are useful tools for empowering girls and women who have experienced violence in the global North countries [63-67]. These studies demonstrated that these initiatives enable the participants to actively negotiate and navigate aggression and violence in relation to their experiences with trauma. However, these programs are rarely classified under the SDP/SGD banner, with the exception of van Ingen's work with Shape Your Life, a trauma-informed boxing program for female and trans survivors of family violence in Toronto, Canada.

However, a few studies have considered similar SDP/SGD programs and their impacts in the global South context, particularly in relation to the physical environment in which these initiatives are deployed. For example, a number of studies considered how SRHR discourses positioned vis-à-vis HIV/AIDS education SDP programming often results in an emphasis on discourses of risk, individualism, and deficiency that correspond to "neoliberal approaches to health promotion and development; emphasizing risk management and individual responsibility, while glossing over the broader social and political factors influencing HIV transmission," [68] (p. 287). Other pertinent work has discussed the SRHR curriculum connected to broader SDP schemes, but still mostly within the framework of HIV/AIDS (e.g., [69,70]). Certainly, this lack of attention to SRHR is perhaps unsurprising considering the disregard to sexuality and the heteronormative backbone of SDP programming, resulting in a marginalization of participants with diverse sexualities (see [71]).

Similarly, the research on SGD and GBV in the global South is limited, although there are a number of studies that suggest GBV prevention strategies should be part of broader programming used for child protection (e.g., [72]). Though other research explores how combative sports, such as martial arts initiatives, have had some success in teaching young women and girls to defend themselves against domestic, sexual and gender-based violence (e.g., [73]); most of these interventions fail to account for broader gender relations and the roles of the physical environment and sustainability practices in relation to program success.

Linking Gender-Based Violence Prevention, Sexual and Reproductive Health, and the Environment

A growing body of scholarly work documents how environmental issues are closely linked to GBV in the home or in public spaces, and draws attention to how gender inequalities associated with capitalism produce specific gendered vulnerabilities and unequal impacts in terms of climate change (e.g., $[4,74,75])$. Indeed, a high prevalence of GBV in global South contexts strongly correlates to an increased physical vulnerability. This vulnerability is exacerbated by extreme weather events due to climate change, thereby reducing the abilities of women and children in particular to adjust or recuperate from natural hazards [4]. Further, recent studies show how the relationships among prescribed gender roles, gendered divisions of labour, social conditioning, and social inequalities connect to issues of public violence (e.g., deforestation). For example, Arora-Jonnoson [74] describes how, during her fieldwork in a rural village in India, one woman she interviewed stated, "there was little point in protecting the forests if [she] could not protect [her]sel[f]," (p. 299). That is, addressing deforestation was unfathomable if no efforts were made to draw attention to the high rates of domestic violence among women in this particular community. 
Relatedly, some gender and development scholars note how notions of population control, sometimes deployed vis-à-vis SRHR curriculum woven into development projects, are framed as "sexual stewardship" [76] (p. 346). Sexual stewardship tenets are evident in the programs and policies put forth in various education and development initiatives that bring together SRHR, GBV, and sustainability practices to animate women as responsible environmental agents who are expected to successfully control their fertility and reproduction [76]. In turn, a number of SGD NGOs actively link these issues through their curriculum, including the organization described in the study herein. As Sasser [76] argues, when such NGOs:

Discursively link population growth, environmental problems, and family planning to women's empowerment, they construct a model of an ideal sustainable development subject: a moral agent who manages her fertility and the environment responsibly through contraceptive use for the greater good. ([76] p. 346)

That is, when development programs aimed at girls and young women (such as those promoted by the Girl Effect) prioritize population control, reproduction and fertility as ways to address climate change, it distracts from issues related to "the structures of industrial accumulation and consumption, justified by the goal of improving macroeconomic measures, that have overwhelmingly produced the material violence of climate change and intensive planetary pollution," [77] (p. 138).

At the same time, it is imperative not to overlook women's agency and essentialize their positions as eternal victims of climate change and docile recipients of the SRHR and GBV curriculum. For example, and in reference to the Nicaraguan context specifically, Bradshaw [78] notes that, although poverty is undoubtedly a central component of vulnerability, it is not the only predictor of understanding the challenges and negative impacts of climate change:

Within Latino cultures, for example, the cult of machismo may make men and not women more likely to suffer the loss of life during an event, whatever their relative poverty, due to their socially constructed roles and associated riskier behaviour patterns in the face of danger. ( $p .628)$

Thus, framing women as the eternal susceptible victims of climate change obfuscates their resilience, agency, and voices. It seems clear, then, that a "gendered focus on climate change must look not only at the vulnerabilities of women and of men, but also at the ways in which their knowledges and situations render them resilient," [4] (p. 683). Stated differently, it is not simply gender norms that dictate the behaviours of individuals. Indeed, cultural norms and a variety of structural, social, economic, and political factors may influence the ways that individuals and communities take up knowledge, programs, and curriculum on a given topic. However, what is apparent is that honing in on the power relations, structural inequalities, and the complex gendered, institutional, and intersectional contexts in which climate change, gender-based violence and SGD take place is central to moving research in this area forward. In the next section, we describe the theoretical tools used in this study to better address such concerns.

\section{Theoretical Framework}

\subsection{Postcolonial Feminist Political Ecology Theory}

Academic work on the links among women, gender, and the physical environment has evolved greatly over the last four decades. Ecofeminism emerged in the early 1970s, while research on women, the environment, and development (WED) came to light in the late 1980s and early 1990s. Taken together, these frameworks laid the foundation for some of the feminist political ecology theories being utilized in more contemporary work.

First, WED approaches typically examined women as victims or caretakers of their surrounding environments while ignoring gender and race as larger categories of analysis [79]. WED was mostly informed by practitioner experience and supports the notion that women are the ones who are most 
negatively impacted by environmental degradation due to "an a priori, and largely universal, gender division of labour", particularly due to their reproductive labour [79] (p. 72). Subsequently, women were essentialized as the key targets of environmental and development planning efforts due to their assumed inherent connection to natural resources, resulting in a "women as both environmental caretakers and victims" trope and adding to their already overburdened caring roles [79]. This approach was largely critiqued for homogenizing women's positions and ignoring gender roles, the fluidity of gender interests, multiple gender relations and identities (see [80]).

The French writer Françoise d'Eaubonne founded the concept 'ecofeminism' through which she pointed to the pressing political possibilities held by women to bring about an ecological revolution [81]. Ecofeminist approaches largely aim to unpack the relationships among gender, social justice and environmental sustainability, offering an epistemology that emphasizes the links between "human and nonhuman, life and nonlife" [82] (p. 53). Ecofeminists explore the woman-nature connection while seeking to "reverse priorities away from capitalist production toward sustainable reproduction and ecology" [82] (p. 54). These perspectives have been critiqued for reinforcing gender binarism and overemphasizing women's relationship to nature through Western lenses that tend to overlook the diversity of women's experiences alongside intersections of race, class, sexuality, disability and colonialism on issues of science and the environment [83].

Feminist political ecology (FPE) emerged in the mid-1990s as a way to better understand and frame relations between gender and the environment as an active process influenced by culture and society. It is a process that originates from, and is grounded in, the operations of power that mitigate the varying access individuals have to control resources at multiple scales, with a specific focus on gendered divisions of labour and gender inequality at its very core [79]. The theories of FPE are also concerned with the ways that gender relations, cultural constructions of hegemonic masculinities and femininities, gender roles, institutionalized gender, gender identity and embodied gender shape climate change, pollution, sustainable development and other environmentally-related factors [4,84]. An FPE approach pays close attention to both the environmental and non-human factors in relation to the intersections of gender, class, sexuality, and race. In this way, gender-related constructs deployed vis-à-vis FPE "shape the way we interpret, debate, articulate and respond to social/natural/techno-scientific phenomena like climate change," [84] (p. 683).

A postcolonial approach expands FPE by directly foregrounding how relations of race, gender, colonialism, and sexuality emerge out of practices related to the physical environment and natural resources. For example, in her ethnographic research with Indigenous Miskito women in Honduras, Mollett [6] contends that the majority of FPE research prioritizes gender at the expense of other categories such as race and colonialism, suggesting that a postcolonial orientation to FPE is direly needed to "show[s] how multiple forms of power and positionings shape natural resource struggles," (p. 146). Postcolonial approaches to FPE usefully re-work and uphold a more complex and nuanced account of the ways that colonialism intersects with racialized and gendered power, acknowledging and yielding a more critical analysis of issues such as:

Natural resource control, distribution, and access as a way to help 'mainstream' gender in development policy and planning, in a more meaningful and plural fashion [ ... ] compelling feminist political ecologists to see race in places we tend to take as race-less, such as 'the environment'. [6] (p. 156)

In short, postcolonial FPE emphasizes the racist structures and inequalities that shape the lives of historically and spatially constituted subjects entangled in "racialized and gendered relationships of power" when understanding natural resource access and authority in global South contexts [7] (p. 123). In the next section, this study explains how these poststructural, postcolonial perspectives conjoin to new materialist standpoints that have become influential in feminist thinking about nature. 


\section{2. (Postcolonial) Feminist Sociomaterialisms}

It is beyond the scope of this paper to fully define the contours and debates related to feminist sociomaterial perspectives. For the purposes of this paper, the essential tenets of feminist sociomaterialisms-or what has come to be recognized as the confluence of new materialisms [85], actor-network theory [86], postcolonial feminist science and technology studies [87,88], and material feminisms [89] - are the material, non-human elements and factors that shape society and human interactions [85], particularly in relation to gender.

Taken together, feminist sociomaterialists consider how agency might be redistributed and co-constructed, with a multitude of actants playing a role in shaping the physical environment [8]. Here, the importance of bodies is still quite relevant for thinking through, and broadly positioning, "empirical actors within a material environment of nature, other bodies, and the socioeconomic structures that dictate where and how they find sustenance, satisfy their desires, or obtain the resources necessary for participating in political life," [85] (p. 19). Indeed, the associations between sporting/(in)active bodies and their environments are important scholarly pursuits for sociomaterialists who study sport, physical activity, leisure, etc. The goal, then, is to see bodies and their environments as intertwined, where humans and non-humans connect in networks that co-constitute each other, where it is possible to "trace more sturdy relations and discover more revealing patterns by finding a way to register the links between unstable and shifting frames of reference rather than by trying to keep one frame stable," [86] (p. 24).

Despite Latour's profound vision of how to shift the foundations of science and politics, Harding [87] contends that he fails to engage with power dynamics. In particular, he ignores feminist and postcolonial perspectives, which "undermines the potential success of [his] transformative projects" (p. 18). Harding therefore looks to postcolonial feminist science and technology studies to decenter traditional Western conception of science, technology, and how progress might be achieved. As Harding [88] proposes, "women and men in different eras and places experience differently the nature and effects of colonialism, imperialism, postcolonialism, neo-colonialism, and the sciences and technologies that these social relations create" (p. 21-22). These concerns are similarly evident in the fields of SDP and SGD, as is explained in the next section.

\subsection{SDP, Postcolonial Feminist Sociomaterialisms and the Environment}

For the most part, SDP has ignored (postcolonial) feminist sociomaterialist perspectives by failing to account for the role and agency of non-human actors as they shape the behaviours and attitudes of those participating in SDP on the ground in diverse contexts and the larger ways that human rights are deployed and taken up (or resisted) by local actors, or targeted beneficiaries. An exception to this is Darnell et al.'s [90] recent work on SDP NGOs operating in Kingston, Jamaica, in which the authors suggest SDP scholars must "begin to move towards a fuller and richer analysis of SDP that would help to show the array of forces and actors (human and non) that influence the organization and deployment of SDP" (p. 97). In fact, they underline that the assemblage of SDP is not merely socially constructed, but is also built by non-human actants (e.g., money, technical support and expertise, real estate speculation, environmental degradation, etc.).

In many ways, these arguments relate to Millington and Wilson's [21] suggestion that more work in socio-cultural studies of sport needs to "de-cente[r], although not de-contextualiz[e], the human body ... namely by 'flattening' physical cultural contexts so as to consider the associations between active human bodies ... and active non-humans" (p. 912). As the authors further contend:

If a hallmark of [physical cultural studies] research is its focus on linking theory, empiricism, and interventionist work, the last of these elements surely requires a broadened view of whom (or what) interventionism might affect and what kinds of inequalities require interventionism in the first place. This would mean bringing new attention to non-human elements of the physical (environment) and 
perhaps inspiring empathy for 'things' - and thus a better and broader sense of interconnectedness and inclusivity. [21] (p. 920).

Similarly, development studies scholars, such as Fatimah and Arora [91], Li [92], and Merry [47] emphasize the importance of the material objects as well as the actors in the production of knowledge as essential spokes to thinking through the wheel of development projects and their perceived success. Equally, however, the items used to measure, for example, surveys, questions, scales, and "technologies of graphic representation", are part in parcel of what Merry [47] refers to as the "technology of statistical knowledge production, developed in a collaborative process by a series of actors, backed by institutions with incentives and money, over a long period of time" (p. 31). Finally, Li [92] stresses the importance of understanding that there are a multitude of objects within any given development project that are beyond our control. They are dynamic forces which cannot be contained despite the best efforts of human administrators, program managers and policy-makers. As she concludes, "the relations and processes with which government is concerned present intrinsic limits to the capacity of experts to improve things. There is inevitably an excess. There are processes and relations that cannot be reconfigured according to plan" [92] (p. 17).

When pulled together, the abovementioned conceptual strands of feminist sociomaterialisms and feminist political ecology studies, when informed by postcolonial approaches, are highly relevant in order to carefully consider how to make the somewhat distant and abstract concepts of environmental sustainability, SGD, climate change—as they collide with race and gender-more tangible, material everyday fixations.

\section{Nicaragua: The Women's Movement, Political Foundations, Sport and Climate Change}

There is not sufficient space here to provide a full backdrop of Nicaragua and the historical underpinnings and political foundations of the women's movement, sport, development, and the environment within this context. Thus, below, key background information is outlined to highlight the contextual social, political, economic and cultural issues that contextualize the current situation in the country.

Following nearly eight centuries of civil war and (re)conquest against Muslim Arabs, the Spanish colonial project began and was marked by the arrival of the first Spanish conquisator in 1522, Gil González de Ávila [93]. Spanish colonization then took place over a three hundred year period and was largely characterized by corruption, Christianization, and military aggression. The mission operated under the support of the Spanish church and state, and the conquistador was a military industrialist who "sought fame, fortune, honor, wealth, and the capture, conversion, and control of the natives," [93] (p. 11). The obliteration of the Indigenous population and the oppressive, exploitative, racialized approach taken to colonization through the encomienda system used Indigenous labour through which Indians (indios-the Indigenous peoples of the Americas) were forced to toil on the lands that was divided by the Spanish colonizers [94]. Thus, a racial hierarchy emerged: "Spaniards (directly from Spain), Creoles (Spanish born in the Americas), Mestizos (born of Spanish and Indigenous lineages) and Indians," [93] (p. 11). As Lancaster [94] remarks:

Most of the real privileges of the colonial epoch are today gone, but the ranking and sorting remains, supported less by economic rights per se and more by the rights and values held to be implicit in the color terms themselves: a colonialism of bodies, trapped by and in discourse; a hegemony, not of colonists, nor even of colonialism per se any more, but of the values produced by colonialism ( $p$. 349, italics added for emphasis).

That is, the ethnic, linguistic, economic, geographical and political divisions and residue from the colonial period still exist today [95].

Nicaragua is currently the poorest country in Central America and one of the most vulnerable countries to climate change impacts, ranking sixth on the Global Climate Risk Index from 1998-2017 [96]. The Nicaraguan government is particularly focused on addressing climate change, especially for 
rural populations. Various studies highlight how Nicaragua is especially prone to damage from hurricanes and tropical storms (e.g., [78]), and is "susceptible to other natural disasters including floods, droughts and landslides, events whose frequency, severity and impacts will be amplified by increased climate variability," [97]. Equally, though, a number of scholars critically discuss the gendered dimensions of climate change in Nicaragua; in particular, by exploring how international development entities working on gender equality and gender-sensitive climate adaptation policies understand the impacts that climate change may have on gender relations, gender roles, identities and divisions of labour [1,3,78]. For example, Gonda [1] describes how the Nicaraguan government promotes the deep connection between women and the environment, such that "women have a natural connection to nature, and therefore that they are especially apt to fight environmental degradation and climate change" (p. 173).

Across Nicaragua, there has been increased deforestation and land degradation, mostly due to policies that promoted expansive cattle-ranching and commercial deforestation during the 1970s [3]. In recent years, heightened climate variability in combination with a sharp increase in soil unpredictability, water scarcity and chronic natural disasters has resulted in food insecurity and poverty at dangerous levels, with " $25 \%$ of rural farming household classified as extremely poor" [97]. This has led to de-agrarianisation across the country, whereby rural populations are moving away from living off the land to increase their livelihood opportunities [98].

In order to understand how GBV prevention and SRHR promotion are taken up and connected to broader discussions of climate change, it is important to outline the gendered political history that informs these terms in Nicaragua. Since the 1970s, legislation in Nicaragua has upheld a deeply entrenched patriarchal gender order perpetuating gender inequalities in Nicaraguan society, with men having primary control over the family and in positions of power across society $[99,100]$. This gender order has been maintained since the election of the Sandinista Party (or the FSLN) in 2007. Indeed, FSLN's launch into power sparked a revolution that ended a 40-year military dictatorship, resulting in more social and economic policies that were created to support women's rights. However, these policies ultimately failed to solidify any systemic efforts that would fundamentally alter patriarchal relations.

Almost ten years later, in April 2018, Nicaragua's political climate became particularly turbulent, with serious human rights violations being committed by government officials and parapolice groups. This crackdown left "324 dead, over 2,000 injured, and hundreds arbitrarily arrested and prosecuted [ ... ] critics of the government's human rights record have increasingly become the targets of death threats, intimidation, online defamation campaigns, harassment, surveillance, assault, and judicial persecution" [101]. Women's and girls' sexual and reproductive health rights, and women's rights more broadly, continue to be challenged in this context, with the FSLN supporting the criminalization of abortion [102]. This is subject to imprisonment for up to two years, regardless of the circumstances (e.g., rape or incest), forcing "women and girls facing unwanted pregnancies to have clandestine abortions, at great risk to their health and lives," [101]. Through this stance, the current government also has failed to demonstrate any tangible commitments to Law 779, which came into effect in June 2012. Law 779 criminalizes violence against women, rejects deeply rooted patriarchal values and directly conflates machismo-or the aggressive paternalism and sense of male entitlement institutionalizes across Nicaragua — while also strongly denouncing violence against women in both public and private spheres [61,102]. Overall, the political, environmental, social and economic experiences of Nicaraguan women outlined here underline some of the challenges involved in locating safe spaces through which to participate in SGD programming, particularly in remote, rural communities mostly predominantly impacted by climate change. 


\section{Methodology}

\subsection{Background on Case Study Organization}

Founded in 1994, the central goal of the local NGO (hereafter LNGO) is to empower Nicaraguan youth in the rural, southern area of the country where they operate through a number of programs and interventions related to sport, environmental awareness education, community development, sexual and reproductive health rights, gender-based violence prevention, youth leadership and income generation.

The Peace Corps partnered with LNGO in the late nineties, when they decided to hold a fútbol tournament to empower youth in the rural community where this organization operates. However, it soon became apparent that, while many of the young men were easily able to access fútbol, the young women were often excluded, had no equipment (fútbol shoes, balls) and were unable to obtain permission from their parents to attend practices (Interview, LNGO Staff Member 3).

Soon after, LNGO closed the tournament for boys and young men, and in 2006 started to realize that the young women needed more than just fútbol. They needed further information about their rights, sexuality and how they could "live being free of violence" (Interview, LNGO Staff Member 3). Subsequently, the focus moved beyond solely on "empowering" young women through fútbol by also including curriculum and workshops centered on SRHR, GBV, healthy environment, environmental sustainability, climate change, and natural resource protection (Interview, LNGO Staff Member 3). A central tenet of the program is to get young women out of their homes (where most domestic, sexual and gender-based violence takes places in this community) and onto the fútbol field to be physically active while simultaneously learning about the abovementioned issues.

During the time of research (2014-2015), LNGO was receiving funding and training in various areas from a number of international and regional donors, including several partners from the sports, environment and development sectors. Perhaps most prominently, they were funded by, and received programmatic input from, an international women's rights NGO (hereafter INGO) that provided local NGOs in approximately 25 global South countries with a universal curriculum based on SRHR education, GBV prevention and environmental sustainability through SGD training. LNGO is primarily made up of local volunteers and paid part-time staff, and provides them with a variety of training and professional development opportunities.

\subsection{Postcolonial Feminist Participatory Action Research (PFPAR): Photovoice, Photocollaging \& Digital Storytelling}

Our methodological approach stems from the theoretical underpinnings of our project, largely grounded in postcolonial feminist standpoints that are useful for "explor[ing] the intersecting power-laden divisions of class, gender, race-ethnicity, migrant status, location, age, and sexuality in diverse contexts, while making analytical connections and networks of resistance between distant places," [103] (p. 35). Participatory action research (PAR) is a qualitative research approach that focuses on prioritizing the participation, perspectives, voices, and lived experiences of individuals and communities that are utmost impacted by the issues under study or who are often the most overlooked by traditional research processes [104,105]. Feminist participatory action researchers suggest that engaging with a feminist lens to PAR is useful for redressing unequal power relations, prioritizing women's perspectives and experiences and generating community-academic collaborations in the spirit of knowledge translation, dissemination and social justice. Infusing the postcolonial into FPAR expands its possibilities even further, by: (1) Prioritizing intersecting relations of race, gender, class, sexuality and colonialism in knowledge production; (2) striving to honour diverse forms of action; (3) centering often overlooked forms of representation and diverse voices; and (4) ensuring ethical engagement with communities most impacted by the issues under study (see also [61,105]).

The study herein used PFPAR involving four modes of data collection, including: (1) In-depth, semi-structured interviews with LNGO staff and the young women participating in its program; 
(2) photovoice (where cameras are given to research participants with the goal of capturing their experiences of a given issue [106]); (3) photocollaging (using the photos generated from photovoice to create arrangements of images, objects and text that convey information about a given topic by research participants [107]); (4) digital storytelling (a video and/or image compilation that tells the 'story' of an individual, community and/or group [104]). We have collaborated on these approaches to explore LNGO's SGD programming throughout the last four years (see $[31,61]$ ).

A translator well-versed in the local Spanish dialect in this community assisted with the interviews (see [61] for further details of the translation process). A total of three organizational staff members from LNGO (Staff Member 1, 2,3) and eleven young women program participants were interviewed. In addition, eighteen young women participants took part in photovoice and poster collaging activities. The young women were given cameras over a three-day period to capture their experiences of the LNGO's SGD program. In particular, they were encouraged by the research team to take images that best conveyed the benefits and challenges they experienced through their involvement in the program.

Following their photovoice activities, the young women gathered for a period of two days to create photocollages on large bristol boards using art supplies, text captions and any other materials they felt were important for expressing their experiences in the program. They created these posters in pairs, with a total of nine posters that were developed and then shared among the group and video recorded with the participants' permission. Hereafter, the group came together to discuss the key themes that arose from the posters, categorizing findings alongside the broad categories of barriers ("barreras," e.g., "violencia"—violence) and enablers ("alientos," e.g., "informacion"—information) that were developed (Figure 1). The first author then used these themes to inform a secondary analysis of the individual photos and collages.

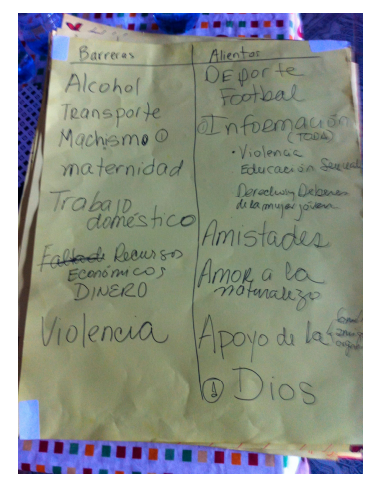

Figure 1. A poster that describes the key themes that emerged following photocollaging analysis with young women participants [61].

The interviews were then transcribed and, along with accompanying photos and postercollages, the data was analyzed along with the accompanying photos and poster-collages using Nvivo 10, a qualitative data analysis software program. The nodes were developed through Nvivo that corresponded to the key themes from the collaborative poster analysis, such as 'barriers-the environment and deforestation', and 'enablers-fútbol'. In keeping with the postcolonial feminist approach, the results of the analysis were then conveyed back to the LNGO and the young women via Skype for confirmation and feedback in an attempt to continue to prioritize their perspectives and control over the data. Hereafter, we worked with the LNGO staff and young women to co-develop a single digital story that attempted to incorporate the photos and poster-collages from the fieldwork. The process of creating the digital story was very intricate and engaging, providing an opportunity through which to "record and document the stories of most significant change" in this community [104] (p. 181).

In accordance with the ethical guidelines outlined by York University's Office of Research Ethics, pseudonyms have been used to protect the identities of all the organizations and participants involved 
in this research. In addition, and following the work of Barker and Smith, we decided to "source photographs" in this paper by using pseudonyms [108] (p. 98). It is believed that this approach upholds our PFPAR orientation by recognizing the young women's experiences as active collaborators in this study and maintains their "'moral ownership over photographs" [108] (p. 98).

\section{Findings}

\subsection{The Feminization of Environmental Responsibility through SGD}

During the photovoice and photocollaging sessions and interviews, the young women and LNGO staff members described the various ways that environmental responsibility was interwoven into the program curriculum. For example, as Staff Member 2 from LNGO stated:

Through football, we can ensure that we have good practices in relation to the environment, to raise awareness within the community. That we should keep safe and clean the environment [ ... ] I'm talking about the environment when the girls are going to play, if they bring in any plastic bag, if they have a water bottle, not to throw it to the floor, but to dispose of their garbage as it should be. And to ensure that the football field is maintained clean, so we have a healthy environment.

The LNGO's curriculum was largely informed by one of its funders, an international women's rights SGD NGO (hereafter INGO) based in Western Europe. The INGO's global SGD curriculum involved an environmental component that included various clean up games, specifically focused on girls in an effort to ensure they "understood the importance of properly disposing of trash," (Staff Member 2, LNGO). For example, the environmental curriculum outlined on the INGO's website describes a game in which girls were blindfolded and then encouraged to try and insert garbage into a can, after which they are encouraged to make an environmental pledge.

While it is difficult to object to curriculum focused on keeping the environment clean, one cannot help but begin to see that there is an inherent assumption in this curriculum - and in the quote from Staff Member 2 above- that (young) women are perhaps more efficient in taking responsibility for the environment, executing environmental chores and related sustainability practices. The potential concern here is that gender relations are being overlooked in that the young women were given the 'core responsibilities' for maintaining a clean football field, all the while being taught how to properly dispose of trash. The challenge is that the curriculum seems grounded in gendered assumptions about their morality in taking care of nature. A related concern is that these new environmental chores are added to their preexisting domestic labour and caring roles, which are described in further detail below.

\subsection{Impelling Hegemonic Gender Identities and Locating Women's Environmental Knowledge}

As noted above, there were cleaning groups that were part of the LNGO's SGD program, where the young women were responsible for tending to garbage, in particular, empty alcohol bottles that the majority of LNGO staff and young women noted were primarily disposed of by the men and boys who participated community football matches or who consumed alcohol while spectating. As Julissa stated, when referring to her photo (Figure 2):

This is a bottle of liquor. And this is sold at the sports field. It is consumed by the [men] and then they just leave the bottles out there. They leave this out there, so oftentimes you have children, small children that will just pick them up and play with these bottles. 


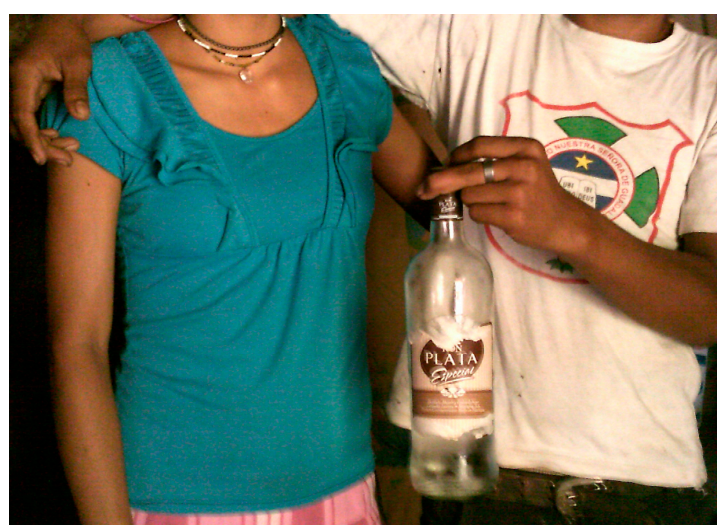

Figure 2. Photograph by Julissa. Untitled.

Similarly, and as Hazell noted, while reflecting on her photo of garbage (Figure 3):

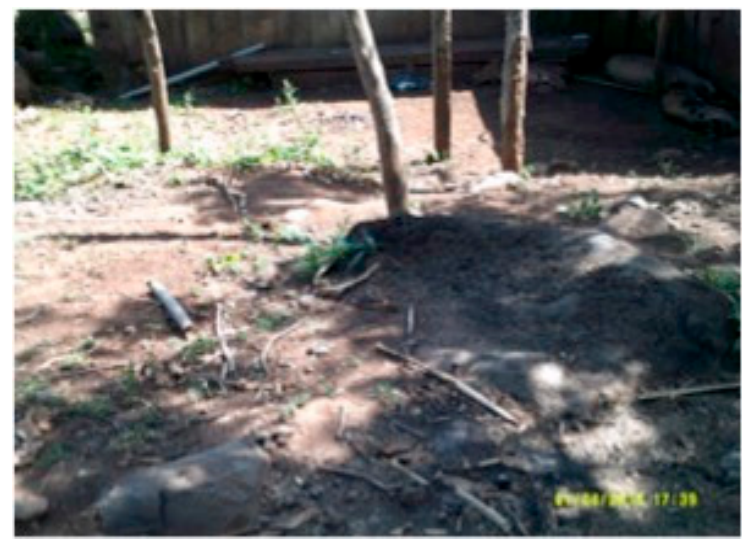

Figure 3. Photograph by Hazell. Untitled.

This photo was taken in front of my house, as you can see. We have cleaning groups. We have four cleaning groups, and if you can see, there is a lot of garbage out there. But what we do is we organize groups to clean, and we collect that garbage, to clean.

Many of the young women spoke of the information outlined in the workshops LNGO held as part of its fútbol festivals and broad curriculum - from condom use to pregnancy prevention; from recycling to creating garbage dumps-the point was that the young women were being taught about how they might access a host of opportunities for self-transformation, self-improvement, and the enhancement of their communities; even in the face of resistance from some family, friends, and community members. For example, Maria described how she continued to attend the LNGO's program even though "community members usually criticize me. They say that we're just looking for men. That we should be at home with our parents. And they just say that we're looking to become pregnant."

Similarly, Julissia explained how she navigated such resistance by simply continuing to attend the LNGO's workshops to see how she could learn more about GBV, SRHR, and sustainability practices:

One of the examples that the information [LNGO] gave us through the workshops and at the different festivals is how to use the condom to prevent pregnancy, and also the sexually transmitted diseases, how to prevent that. Something else is what we can do with the plastic, with garbage. How can we reuse that? We can work, or we can build a garbage dump, or you can sweep it up.

Julissia proceeded to discuss the photo of the t-shirt she had, with the slogan "I use condom always" that she won for coming in first place in a fútbol tournament, something that she continued to wear while practicing fútbol in her community, despite being mocked by local boys and men. In 
spite of this, she was committed to continuing to wear the t-shirt and to cleaning up the alcohol bottles, ignited by the information and knowledge LNGO had relayed about how these activities may make her challenge gender norms and ignite social change in her community.

Staff member 2 further commented on the importance of the young women taking responsibility for the environment for the sake of their health and the health of others:

For us-we as [LNGO], it is important to create the link, to relate those issues. As a criteria that we had set up in the activities, we don't use disposable dishes or disposable plates or cups because that creates garbage. And oftentimes this is garbage that is not easily recyclable or perhaps is not. So these are issues that are-have a relationship with health, with taking care of us. But also taking care of the environment in which we live. It's part of the living together, the harmonious relationship in which we need to live. It's like a triangle. We, men, environment, it's creating an equal footing. It is the nation among men and women, but also with the environment. Creating a balance, an equal footing among those three. We always just try to do that, to preserve the environment.

Certainly, this balance was critical to the operation of LNGO in this community. However, the difficulty here was that the cleaning groups potentially conflicted with some of the primary goals of the SGD program, which was to use fútbol, a predominantly masculine sport in Nicaragua, as a tool to disrupt gender norms in the community and to bring girls outside of their homes, since the young women experienced the greatest amount of domestic and sexual violence within the walls of their own homes. However, the creation of single-sex cleaning groups alongside a SGD program such as the initiative administered by LNGO risks constructing cleaning as an "exclusively female chore by the climate change projects, reinforce[ing] 'traditional' gender roles that are 'traditional' only in the view of the project" [1] (p. 181-182). Thus, and in many ways, the creation of the cleaning groups may perilously reinforce women's fixed roles, where "women's labor and knowledge needs to be used for purposes of sustainability" [74] (p. 304).

Along these lines, many of the young women described the struggles involved in disrupting the traditional gender roles and negotiating their freedom from the domestic duties and violence. Indeed, such issues were captured in the photos by Petrilla (Figure 4) that feature images of a tied-up pig and a woman as she remains in the home, caring for children, cleaning and cooking:

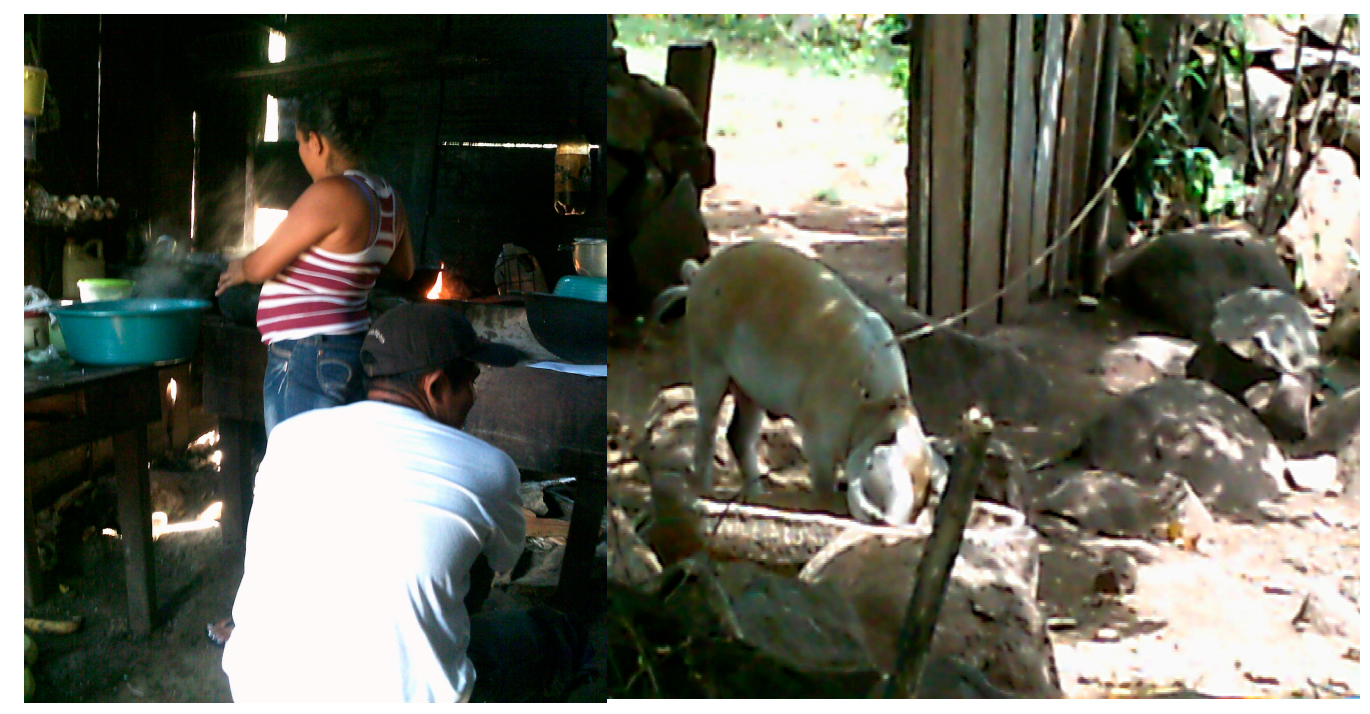

Figure 4. Photographs by Petrilla [31]. Untitled.

You see in our pictures that women have dedicated themselves to domestic activities, you see a woman cooking, and a man simply sitting there waiting for the food to be taken to him. And we as [young women] are taught that we need to be mothers. So usually in our communities we see young women who are 14 or 15 years old already pregnant [ ... ] Another obstacle, if you see this pig. We 
know this is a domestic animal, so we are doing domestic chores. But if you can see, the pig is with a rope, tied up. It is as when our parents do not allow us to leave the house, and we are sort of prisoners in our own homes ([31]).

Certainly, one of the central tenets of LNGO's program was to get these young women outside of their homes, actively working to prevent their social isolation, avert GBV, and better understand how to uphold and enforce their SRHR. However, eight out of the eleven interviewees described how an increasingly heavy and lengthening rainy season kept them inside their homes where they experienced sexual violence and where they were rarely unmoored from their domestic obligations and traditional gendered roles. In addition, ten of the eleven young women described their experiences of feeling overburdened by their domestic responsibilities and obligations, not only to address cleaning their homes, communities, and caring for family and friends, but also to navigate the challenges of climate change and deforestation, further described in the section below.

\section{3. "They Chop the Trees": Landslides, Cement Barriers, and the Gendered Implications of Climate Change}

Deforestation in the rural community where the LNGO operated was on the rise. There, most community members are small-scale farmers producing maize, beans, and some vegetables on small plots of land that have been severely degraded due to the increasing use of herbicides and commercial-led deforestation. These factors, in combination with a lengthening rainy season due to climate change, also resulted in increasing landslides and a heightened propensity to the occurrence of natural disasters. As a result, LNGO's SGD program focused on educating the young women about the importance of forest preservation. Alongside their participation in fútbol activities, the program encouraged the young women to plant trees and use barriers/blocks made of cement (as seen in Figure 5, below) to protect their roads and homes from the landslides. As Maria explained in relation to her photo:

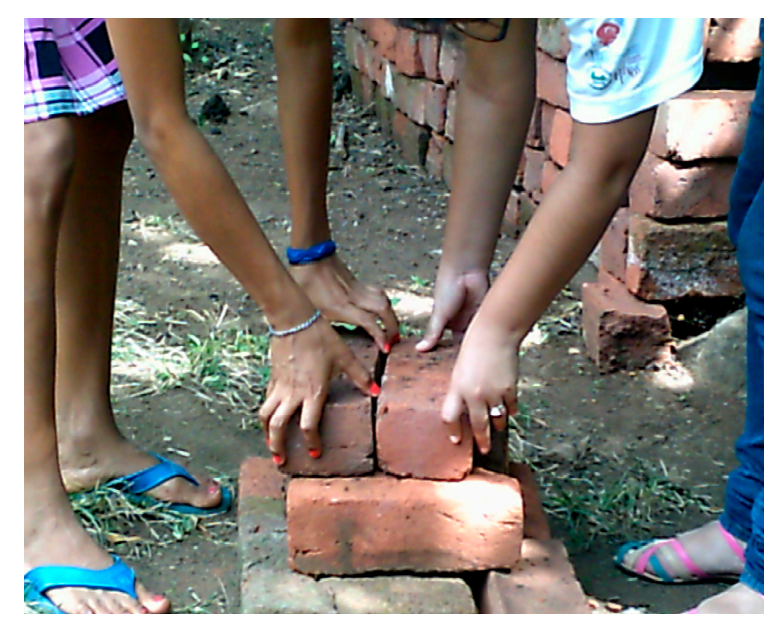

Figure 5. Photograph by Maria. Untitled.

Maria: In this picture it reflects the environment. It shows dirt, and then it requires some cleaning. So that's what I'm trying to reflect there.

Interviewer: What do you mean cleaning?

Maria: If you see, when I took the picture I was thinking that we need to clean this area here. You see right here in this area, it has dirt and leaves and no trees here and that there's some cleaning that needs to be done.

Interviewer: Okay, where was this taken?

Maria: This was taken on the street. And this is a cement barrier so water won't go down, it detains leaves. So it's just a stop, and it's a barrier to protect-so there you see the tree is being 
protected by the stones, by the rocks. And this, you can see them on the roads, so you are not able to walk through those areas. You are not able to go through those areas. So we want to prevent that.

Julissa concurred with Maria's observations as she explained her photo (Figure 6):

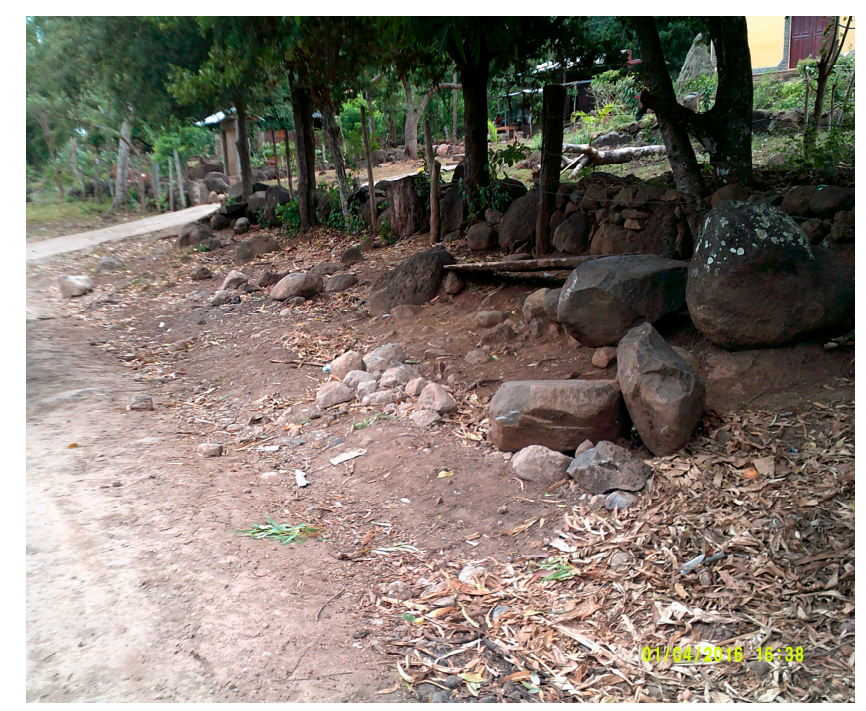

Figure 6. Photograph by Julissa. Untitled.

Julissa: I took this. I was on my way to the football field, to the sports field. About this topic, we have received workshops from [LNGO] related to deforestation, the preservation of the forest. However, there are people that are not interested, and they do this. They chop the trees, so you have deforestation that is huge. They cut down the trees.

Interviewer: So [LNGO] has workshops on this topic?

Julissa: Oh, yes. How to recycle, how is it that we can help to reforest, build up the forest in a place that has been desolated.

However, the young women described how most often these cement barriers could not replace the trees in battling an increasing rainy season, seldom being able to protect the trees and prevent the landslides that would consistently erode, block, and destroy any roads or pathways the participants hoped to use to attend the LNGO's SGD program and flee the violence they often experienced in their homes.

\subsection{Non-human Actors, Social Isolation and the Gendered Climate Change}

As the photos demonstrate, a lengthening rainy season and increased landslides severely impacted transportation for young women, not only resulting in their inability to attend the SGD program and fútbol tournaments, but also intensifying their social isolation and exposure to violence in their own homes. It was thus nearly impossible for the LNGO programmers to account for the ways that these non-humans, such as roads, mud, cement barriers, trees, etc. impacted their efforts to (somewhat ironically) educate and impart to these young women and girls about their SRHR, sustainability practices and environmentalism.

It is important to highlight that during the photovoice and photocollaging activities, many young women captured positive images of their surrounding community, where they described unique flowers, thriving trees, a (seemingly) pristine nearby lake, and a well-used (and revered) fútbol pitch. However, the majority of young women took photos of rocks, washed out roads, tied up pigs, lonely teddy bears, and toy helicopters to discuss the ways that climate change contributed to feelings of seclusion and their increased susceptibility to experiences of violence.

As Gabriella explained in reference to the challenge of traveling throughout her community (Figure 7): 
I took this picture in my community. One of the difficulties that we face on this road, there is a gorge which is very bad, very deep. And there are difficulties, many of them, because we transport ourselves in a vehicle and the lane is very narrow, so just passing through it is very difficult. And we have to pass through there if we want to play when we go far away [31] (p. 284).

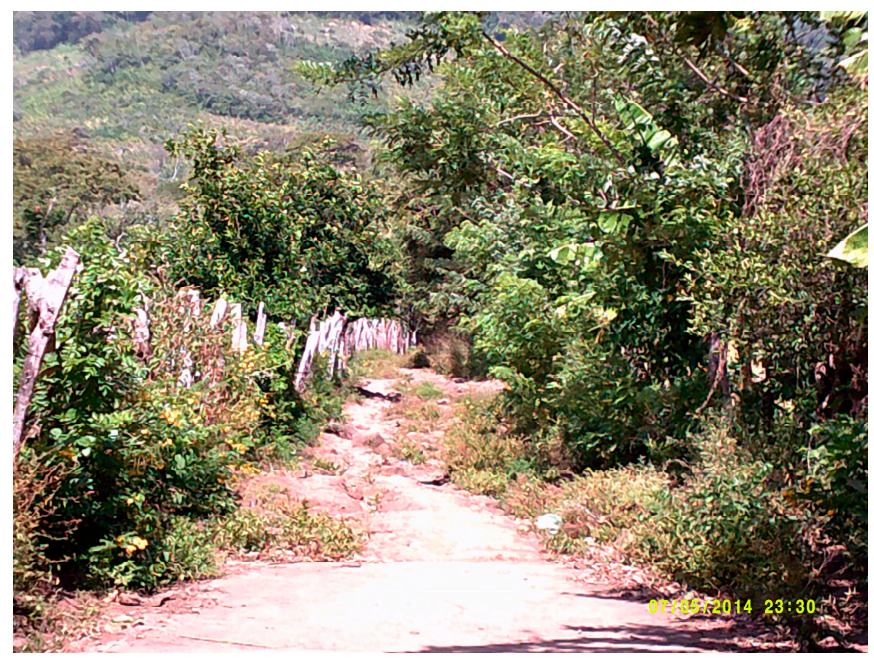

Figure 7. Photograph by Gabriella ([31,61]). Untitled.

Camilia assented as she discussed her photo of a toy helicopter and teddy bear (Figure 8):

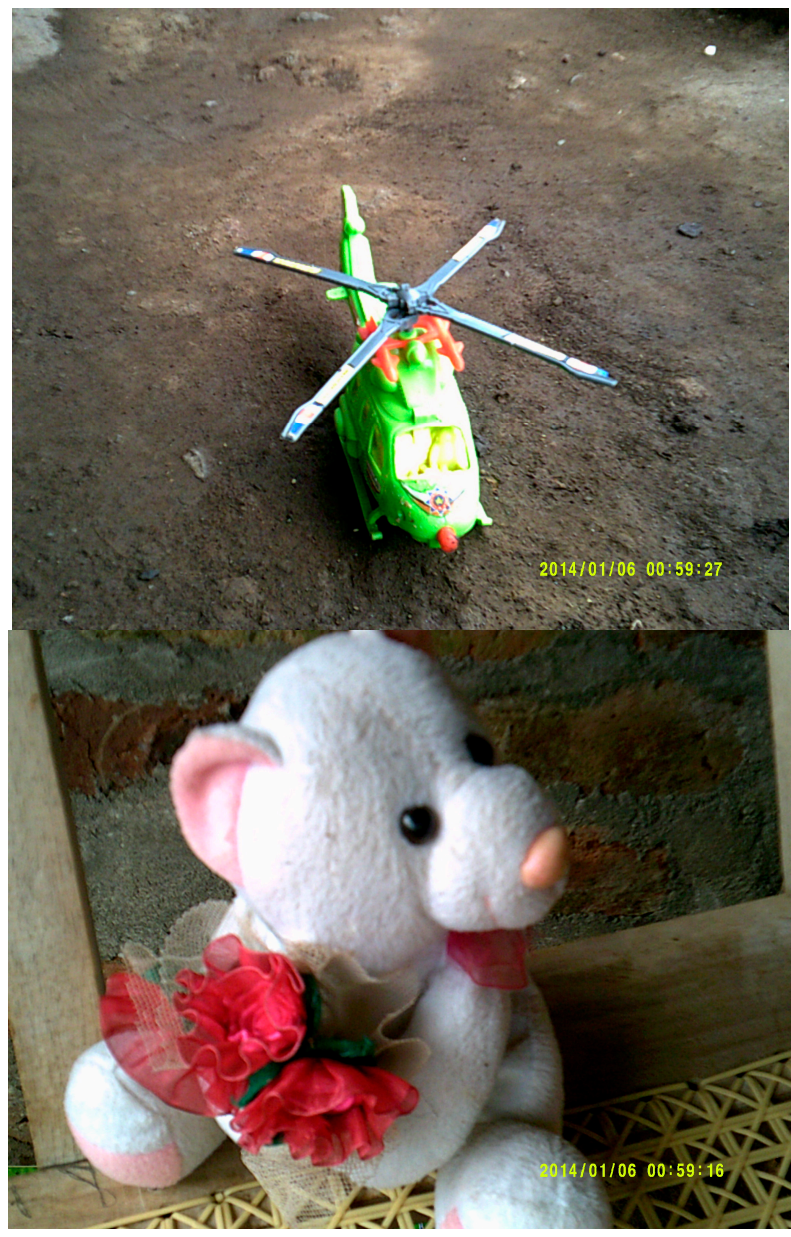

Figure 8. Photographs by Camilia. Untitled. 
This is something that we would never, ever be able to achieve. To fly to some workshop in a helicopter ... it would be very difficult. And this is a little bear. I took this picture at my house. That was the way we used to feel, you know, prior to LNGO, it was just like a little bear that was prisoner and it wouldn't go out-couldn't go out. Nobody would visit us and we couldn't get out of the house.

Camilia's concerns connect to a photo taken by Omara of white tourists who she saw driving throughout her community in their sedan. She noted how their privilege and freedom to travel in and out of the area seemed in stark contrast with her inability to access and afford the same luxuries (Figure 9):

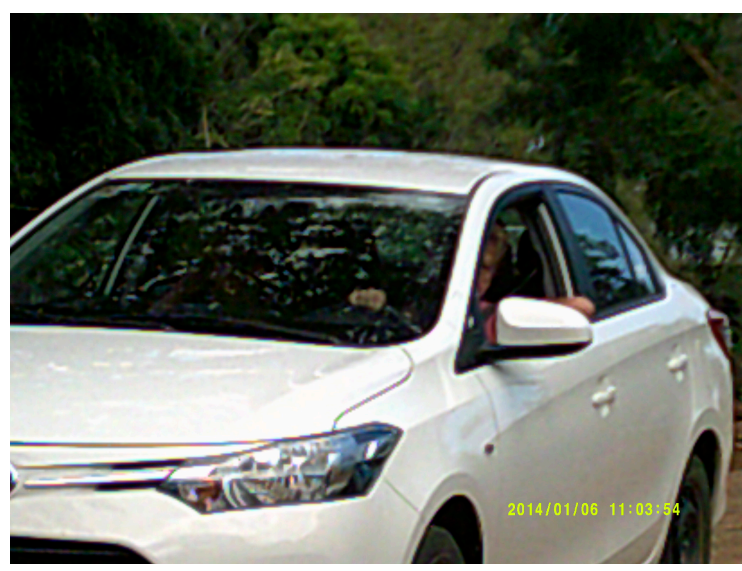

Figure 9. Photograph by Omara [61]. Untitled.

Omara: Perhaps I might not be able to buy this car, however, if some time in the future I was able to buy it; it would mean a whole lot for me. It would mean happiness. That's the reason why I liked it, because perhaps I might not be able to buy it, but I can have it in a picture. It's my car [61] (p. 13)

Indeed, it was not lost on many of the young women interviewed that their race, gender and socio-economic status played a large role in the disadvantages and hardships they experienced. Despite this, through their interviews, the photos and photocollages, the young women communicated the importance of learning key information about their SRHR, and on how to prevent GBV through the workshops offered by the LNGO. As Andrea explained:

I like to talk about violence, and I like to learn about my health and the health of the body. How we as girls take care of your own body. They [LNGO] really give us good training workshops. We do a lot of games. LNGO talks to us about sexuality. They teach us how to prevent diseases, how to ensure that our body's kept clean, what are some of the things that we need to do, how to prevent diseases. And if we're talking about sexual topics, how to prevent pregnancy, unwanted pregnancies.

In the quote above, it seems particularly apt that the onus was on these young women to learn about their SRHR, how to defend themselves against violence and disease while simultaneously protecting themselves (and their communities) from landslides, cleaning up their environment and preventing pollution. In turn, many of the young women struggled to make it to the workshops due to a suite of non-human factors: Washed away roads, broken bicycles destroyed by rocky journeys, and even the tree stumps that once helped to prevent natural disasters from occurring in the first place. Thus, in many ways, the young women were responsible for finding a way to mitigate climate change and pollution while concurrently attending the workshops that were teaching them how to clean their environments and plant trees in the first place. In addition, they were also to absorb information about their SRHR and GBV prevention strategies so they could assert their rights and avoid violent situations.

\section{Discussion}

Here, we draw on the findings highlighted above to stimulate dialogue in relation to the place of young women's knowledge in and through SGD programming when it comes to issues related to 
the environment, SRHR, and GBV prevention. In doing so, we outline the results of our empirical work to argue that future studies would do well to consider the connections and relationships among the environment in relation to how SGD programs (and SDP interventions more broadly) are conceptualized, implemented, and taken up by participants, such as the young women discussed herein. To contextualize and frame the discussion, we focus on four key areas: (1) The girling of environmental, sexual, and reproductive responsibility in/through SGD; (2) the question of how to attend to the social and material constraints faced by SGD participants, their communities and other relevant stakeholders; (3) the role of non-humans in SGD programming; (4) the confluences of SRHR, GBV, and the environment in and through SGD.

In the first place, and in line with broader discourses associated with the girl effect mantra, it seems clear that the young women involved in this particular program are being positioned by the LNGO and other actors as agents of change who are encouraged to actively participate in addressing sustainability, environmental protection, climate change, gender equality, gender-based violence prevention, and sexual and reproductive health rights promotion in and through SGD programming. Certainly, these young women are being asked to try and overcome the social, material, and environmental constraints they face, such as a culture of machismo, poverty, and climate change, in an effort to improve their own lives and the lives of their community members. That is, and in many ways, it seems that being responsible for one's body is inextricably linked to being responsible for land and the environment [109].

At this point, we must emphasize that we do not believe any staff or SGD programmers are trying to increase the challenges that these young women face. Undeniably-and based on our empirical work - they are trying to improve the lives of these young women. And while we are not against promoting SRHR and GBV prevention in and through SGD programming and the necessity that such programs are increasingly positioned to highlight the prominence of environmental issues, our concern is that the structural and enduring colonial and socio-economic inequalities that have situated this particular community in Nicaragua as one with high rates of violence; and where gender and race and entangle with "everyday practices of livelihood and natural resource struggles" [7] (p. 123), remain somewhat obscured.

Put differently, we seek to question the idea that these young women should be impelled to be 'good global girl citizens' who are being summoned to save the environment without addressing whether they might have the resources or capacity to do so [110]. In turn, a postcolonial feminist approach to FPE, when informed by feminist sociomaterialisms, may ask how to better understand the ways that values produced by colonialism might unintentionally permeate these types of programs and the non-human actors enmeshed in their very fabric, or at the very least, foreground how the race, gender, and colonialism shape the politics of natural resource control and access in the global South [7]. How might such a lens infuse nuances and forge, for example, a more complex analysis to locate how colonialism, racialized and gendered power play crucial roles in the ways that SGD programs are deployed, implemented, and taken up by participants [109]?

For example, Harding [87] points to the ways that European expansion led to the exploitation of other cultures' knowledge systems, where Europeans "absorb[ed] into their own sciences useful information about the new environments they encountered, as well as new research technologies and conceptual frameworks used in other cultures" (p. 137). Likewise, Harding [87] describes how "a major expansion of resources available in development processes came from the appropriation of the traditional land rights" and the work of female labourers (p. 141). Thus, when young women are asked to take responsibility for their environment and land through SGD programming, it seems critical to question how their natural resources and lands became so deteriorated and exploited in the first place. How might we reverse the imperial gaze such that we ask how those in the global North/West have contributed to, and are in many ways, responsible for, global warming, climate change and environmental degradation experienced in the SGD program seen here, by Nicaraguan young women in the global South (see [111])? Ultimately, our trepidation is that programs that combine SGD with environmentalist concerns may unintentionally ask young women to "accommodate themselves 
to existing norms and structures rather than that the structures be changed to accommodate their subjective positions, needs and ideas to redress disadvantage" [112] (p. 187).

However, the LNGO's program provided a crucial yet subversive space to spark pertinent conversations among these young women about their rights (with little capacity to actually challenge the very institutions that uphold them). It opened a fissure and catalyst of sorts to encourage the participants to leave the violent environment in their homes and circumvent the non-human elements such as washed away roads, and further to utilize these same non-human materials (e.g., policies, laws and information about their rights and soccer balls) to support their successful participation in the program. Each of these actants played a role in determining the physical environment in which these young women were to successfully participate in SGD; and yet, the program could not prevent landslides from keeping young women in their houses. Certainly, and no matter how many sustainability practices the young women grasped through the curriculum, they could not control the increasingly lengthening rainy season that washed away the roads used to escape to the fútbol program. Furthermore, irrespective of how many bottles were picked up, and despite the number of environmental education sessions the young women attended through the SGD program, it seemed that these non-human elements were ones that the young women pointed to as significantly shaping, and often hindering, their abilities to benefit from the LNGO's program. These findings resonate with other development studies, such as Li [92], who advise that no matter how humans might want to control the non-human through development projects, there will always remain "dynamic forces which cannot be contained" (p. 17).

Further, the LNGO participants' photos also indicated the deeply important role that non-human factors played in the environmental governance of the program. Here, non-humans "are not simply pliant objects, which human actors can wilfully control [ ... ] but rather they try to resist control by human actors, also because they may be embedded in alternative webs of relations," [91] (p. 26). Equally, then, the ways the human and non-humans might form a constitutive network of social relations held together within the framework of SGD need to be accounted for. A young woman could move a cement barrier to try and protect a tree from a landslide so that the road outside her house will not be washed away, but despite her human expertise, she is unable to leave her home to attend the LNGO's SGD program. Thus, she cannot alter how SGD programming evolves (also see [112]). In turn, and argued elsewhere, more empirical studies need to be conducted to better understand how these active mediators, and collectives (i.e., human, non-human, and the relations in-between) impact a given SGD and broader SDP program $[90,112]$. In many ways, the photovoice and poster-collaging activities tried to make the "'immaterial and distant issue [of] climate change]' [113] a concrete everyday environmental preoccupation [by] generating information and knowledge on climate change that speaks to the people in the specific Nicaraguan context" [1] (p. 182). Our study then expands on research that demonstrates how visual and digital participatory approaches are useful for probing more deeply into participant experiences and better pinpointing the nuances and multiple relations within which research is conducted (e.g., [114]).

Finally, and in relation to SRHR, GBV, and the environment in and through SGD, our findings motion to other feminist studies that explore the logic of vulnerability that permeates the discourses of gender and development programs more broadly in peacekeeping [10]; menstrual hygiene management [51], and feminist reproductive politics [77] in global South contexts. Taken together, this literature conveys how women, especially young women, need to be first positioned as vulnerable victims before they may be empowered (ideally, economically). It therefore seems critical to understand the deep connections between the material violence of climate change and the gender-based violence produced in its wake. The challenge, then, in asking young women to be responsible for learning about climate change, sustainability practices, and preserving their environments successfully through SGD programming, is that it potentially creates a diversion from the fact that "it is the structures of industrial accumulation and consumption, justified by the goal of improving macroeconomic measures, 
that have overwhelmingly produced the material violence of climate change and intensive planetary pollution," [77] (p. 138).

Murphy [77] also points to the ways that young women in the global South are often asked to lower their fertility in the name of "planetary environmental damage" (p. 139), while Bobel [51] notes how young women's bodies need to be respectable and dignified before they can contribute to any kind of development of their communities and countries, environmental or otherwise. While sexual and reproductive health rights have been linked to "safe and sustainable communities" [52], it is important to heed to Arora-Jonnson's [74] warning that knowing one's rights and having laws in place are simply not enough. Instead, it is "the structures and unequal relations that cause disadvantage to persist need to be challenged" (p. 306). There is also an implicit understanding in the SGD program that young women need to be responsible for violence prevention and gaining SRHR knowledge, and that their agency in locating knowledge on GBV prevention and SRHR promotion will be exerted in productive and socially transformative ways. It is difficult, then, to be concerned about the pressure placed on young women to learn to tame their bodies, clean their environments in order to avert climate change, halt their fertility, and prevent violence. As Ahmed [115] powerfully cautions:

Being a girl is a way of being taught what it is to have a body; you are being told; you will receive my advances; you are an object; thing, nothing. To become a girl is to learn to expect such advances; to modify your behaviour in accordance [ ... ] Indeed, if you do not modify your behaviour in accordance, if you are not careful and cautious, you can be made responsible for the violence directed toward you. (p. 26)

Future research on SGD would do well to heed to Ahmed's warnings, to think through the need to teach young women to "modify their behaviours" without addressing the material and structural inequalities that they face. At the same time, it is problematic to ask NGOs to address such grand inequalities. Indeed, these issues often seem beyond the scope of their work and out of reach.

\section{Conclusions}

In summary, this article has attempted to contribute to sociological and environmental studies of SDP in four key ways, specifically by: (1) Demonstrating how gendered hierarchies, roles and relations operate and are reinforced through SGD—and sport more broadly-through the pursuit of neoliberal and colonial development in the guise of sustainable practices; (2) underlining the complex gendered, racialized and economic relations that operate to impel both human and non-human elements in shaping SGD programming in unintended ways; (3) showing how the prevention of violence to the land and physical environment is deeply enmeshed with preventing violence against young women's bodies, and to broader decolonization efforts-issues that must move to the vanguard of SGD and SDP studies [109].

Furthermore, this study has explored how environmental degradation, pollution and climate change are experienced across communities in diverse and inadvertent ways. Here, the care work and onus of protection seems to fall on young women as part of broader gendered divisions of labour [109]. That is, women are asked to do the curative labour while those most responsible for environmental damage and violence (e.g., industry, etc.) seem to continue to perpetuate and fail to prevent such destruction for occurring in the first place [109]. Despite the Sandinista government's claim to encourage all Nicaraguans to live in "harmony with Mother Earth" [1] (p. 173), the onus seems to mostly fall on (young) women to locate and maintain such harmony.

Future studies may critically consider how SGD programs define, take up and implement policies related to physical and sexual abuse and harassment and child protection across programs in different contexts, and might also critically explore how the surrounding physical environment influences and shapes the ways participants experience such concepts. Further studies might also ask how SGD/SDP potentially reinforces gendered polarities, when the programs tack on environmental sustainability strategies and climate change adaptation tools. There is still much to be known about how SGD/SDP 
programming influences gender relations and re-works how the environment is managed. Last but not least, it would be better to understand what the role of nonhumans is in these kinds of programs.

Author Contributions: Hayhurst led the initial conceptualization of the paper-including the methodological approach, draft preparation, writing-reviewing and was responsible for funding acquisition; subsequent development of the paper was evenly distributed across both authors.

Funding: The research outlined in this paper was funded by a Social Sciences and Humanities Research Council of Canada (SSHRC) Banting Postdoctoral Fellowship (BPF-SSHRC-00022) to the first author. The APC was funded by a York University Library Open Access Fund.

Acknowledgments: The research team sincerely thanks the young women and staff who took the time to collaborate on this study and share their stories, images and experiences. We are grateful to Amanda De Lisio and the two anonymous reviewers for their insightful comments on earlier drafts of this manuscript. We would also like to thank and recognize the research support of Mitchell McSweeney and Cecilia Eugenia Falla for her translation services. Any opinion, findings, conclusions or recommendations expressed in this material are those of the authors. This article draws from a paper that was presented at the 'Sport and Sustainable Development Symposium' at the University of Toronto, Canada on 8 June 2017.

Conflicts of Interest: The authors declare no conflicts of interest.

\section{References}

1. Gonda, N. Revealing the patriarchal sides of climate change adaptation through intersectionality: A case study from Nicaragua. In Understanding Climate Change through Gender Relations; Buckingham, S., Le Masson, V., Eds.; Routledge: London, UK, 2017; pp. 173-189. ISBN 978-131-566-160-5.

2. Women Win. Intro. Available online: https://guides.womenwin.org/gbv/intro (accessed on 28 June 2019).

3. Gonda, N. Climate change, "technology" and gender: "Adapting women" to climate change with cooking stoves and water reservoirs. Gender Technol. Dev. 2016, 20, 149-168. [CrossRef]

4. Moosa, C.S.; Tuana, N. Mapping a research agenda concerning gender and climate change: A review of the literature. Hypatia 2014, 29, 677-694. [CrossRef]

5. Giulianotti, R.; Darnell, S.; Collison, H.; Howe, P.D. Sport for development and peace and the environment: The case for policy, practice, and research. Sustainability 2018, 10, 2-15. [CrossRef]

6. Mollett, S. Gender's critical edge: Feminist political ecology, postcolonial intersectionality, and the coupling of race and gender. In The Routledge Handbook of Gender and Environment; MacGregor, S., Ed.; Routledge: London, UK, 2017; pp. 146-159. ISBN 0-415-70774-9.

7. Mollett, S.; Faria, C. Messing with gender in feminist political ecology. Geoforum 2013, 45, 116-125. [CrossRef]

8. Esmonde, K.; Jette, S. Fatness, fitness, and feminism in the built environment: Bringing together Physical Cultural Studies and sociomaterialisms, to study the "obesogenic environment". Sociol. Sport J. 2016, 35, 39-48. [CrossRef]

9. Grosz, E. Feminism, materialism, and freedom. In New Materialisms: Ontology, Agency and Politics; Coole, D., Frost, S., Eds.; Duke University Press: London, UK, 2010; pp. 139-158. ISBN 978-082-239-299-6.

10. Shepherd, L. Gender, UN Peacekeeping and the Politics of Space; Oxford University Press: London, UK, 2017; ISBN 978-019-069-943-7.

11. True, J. The Political Economy of Violence Against Women; Oxford University Press: London, UK, 2012; ISBN 978-019-975-591-2.

12. UN Inter-Agency Task Force on SDP. Sport for Development and Peace: Towards Achieving the Millennium Development Goals. 2005. Available online: www.sportanddev.org (accessed on 4 November 2016).

13. Cantelon, H.; Letters, M. The making of the IOC environmental policy as the third dimension of the Olympic movement. Int. Rev. Sociol. Sport 2000, 35, 294-308. [CrossRef]

14. Chernushenko, D. Greening our Games: Running Sports Events and Facilities that won't Cost the Earth; Centurion Publishing \& Marketing: Ottawa, ON, Canada, 1994; ISBN 0-9697571-5-8.

15. Lenskyj, H.J. Sport and corporate environmentalism: The case of the Sydney 2000 Olympics. Int. Rev. Sociol. Sport 1998, 33, 341-354. [CrossRef]

16. Mol, A.P.J. Sustainability as global attractor: The greening of the 2008 Beijing Olympics. Glob. Netw. 2010, 10, 510-528. [CrossRef]

17. Stoddart, M.J. "If we wanted to be environmentally sustainable, we'd take the bus": Skiing, mobility and the irony of climate change. Hum. Ecol. Rev. 2011, 18, 19-29. 
18. Millington, B.; Wilson, B. Super intentions: Golf course management and the evolution of environmental responsibility. Sociol. Q. 2013, 54, 450-475. [CrossRef]

19. Millington, B.; Wilson, B. An unexceptional exception: Golf, pesticides, and environmental regulation in Canada. Int. Rev. Sociol. Sport 2014, 51, 446-467. [CrossRef]

20. Millington, B.; Wilson, B. Golf and the environmental politics of modernization. Geoforum 2015, 66, 37-40. [CrossRef]

21. Millington, B.; Wilson, B. Contested terrain and terrain that contests: Donald Trump, golf's environmental politics, and a challenge to anthropocentrism in Physical Cultural Studies. Int. Rev. Sociol. Sport 2017, 52, 910-923. [CrossRef]

22. Wilson, B. Sport and Peace: A Sociological Perspective; Oxford University Press: Oxford, UK, 2012.

23. Kidd, B. A new social movement: Sport for development and peace. Sport Soc. 2008, 11, 370-380. [CrossRef]

24. Willis, O. Sport and development: The significance of mathare youth sports association. Can. J. Dev. Stud. 2000, 21, 825-849. [CrossRef]

25. Wheaton, B.; Roy, G. Exploring critical alternatives for youth development through Lifestyle Sport: Surfing and community development in Aotearoa/New Zealand. Sustainability 2017, 9, 1-16. [CrossRef]

26. Millington, R.; Darnell, S.; Millington, B. Ecological modernization and the olympics: The case of golf and Rio's ‘Green' Games. Sociol. Sport J. 2018, 35, 8-16. [CrossRef]

27. Daly, H.E. Beyond Growth: The Economics of Sustainable Development; Beacon Press: Boston, MA, USA, 1996; ISBN-10: 0807047090.

28. Andrews, N.; Bawa, S. A post-development hoax? (Re)-examining the past, present and future of development studies. Third World Q. 2014, 35, 922-938. [CrossRef]

29. Jeanes, R.; Magee, J. Promoting gender empowerment through sport? Exploring the Experiences of Zambian female footballers. In Global Sport-For-Development; Adair, D., Schulenkorf, N., Eds.; Palgrave Macmillan: London, UK, 2013; pp. 134-154.

30. Saavedra, M. Dilemmas and opportunities in gender and sport-in-development. In Sport and International Development; Levermore, R., Beacom, A., Eds.; Palgrave Macmillan: New York, NY, USA, 2009; pp. 124-155.

31. Hayhurst, L.M.C.; Sundstrom, L.M.; Arksey, E. Navigating norms: Charting gender-based violence prevention and sexual health rights through global-local sport for development and peace relations in Nicaragua. Sociol. Sport J. 2018, 35, 277-288. [CrossRef]

32. McDonald, M. Imagining neoliberal feminisms? Thinking critically about the US diplomacy campaign, 'Empowering women and girls through sports'. Sport Soc. 2015, 18, 909-922. [CrossRef]

33. Forde, S.D.; Frisby, W. Just be empowered: How girls are represented in a sport for development and peace HIV/AIDS prevention manual. Sport Soc. 2015, 18, 882-894. [CrossRef]

34. Hershow, R.B.; Gannett, K.; Merrill, J.; Braunschweig Kaufman, E.; Barkley, C.; DeCelles, J.; Harrison, A. Using soccer to build confidence and increase HCT uptake among adolescent girls: A mixed-methods study of an HIV prevention programme in South Africa. Sport Soc. 2015, 18, 1009-1022. [CrossRef]

35. Szto, C. Serving up change? Gender mainstreaming and the UNESCO-WTA partnership for global gender equality. Sport Soc. 2015, 18, 895-908. [CrossRef]

36. Meier, M. The value of female sporting role models. Sport Soc. 2015, 18, 968-982. [CrossRef]

37. Chawansky, M.; Mitra, P. Family matters: Studying the role of the family through the eyes of girls in an SFD programme in Delhi. Sport Soc. 2015, 18, 983-994. [CrossRef]

38. Fisher, C.D.; Dennehy, J. Body projects: Making, remaking, and inhabiting the woman's futebol body in Brazil. Sport Soc. 2015, 18, 995-1008. [CrossRef]

39. Thorpe, H. Action sports for youth development: critical insights for the SDP community. Int. J. Sport Policy Politics 2016, 8, 91-116. [CrossRef]

40. Thorpe, H.; Chawansky, M. The 'girl effect' in action sports for development: The case of the female practitioners of Skateistan. In Women in Action Sport Cultures: Identity, Politics and Experience; Thorpe, H., Olive, R., Eds.; Palgrave Macmillan: London, UK, 2016; pp. 133-152. ISBN 978-1-137-45797-4.

41. Brymer, E.; Downey, G.; Gray, T. Extreme sports as a precursor to environmental sustainability. J. Sport Tour. 2009, 14, 193-204. [CrossRef]

42. Women Win. What is Gender-Based Violence (GBV)? 2018. Available online: http://guides.womenwin.org/ gbv/conflict/context/what-is-gender-based-violence (accessed on 25 February 2019). 
43. UN Women. Facts and Figures: Ending Violence Against Women. 2018. Available online: http://www. unwomen.org/en/what-we-do/ending-violence-against-women/facts-and-figures (accessed on 29 June 2019).

44. World Health Organization (WHO). Global and Regional Estimates of Violence Against Women: Prevalence and Health Effects of Intimate Partner Violence and non-partner sexual violence. 2013. Available online: http: //www.who.int/reproductivehealth/publications/violence/9789241564625/en (accessed on 12 January 2019).

45. Mitchell, C.; de Lange, N. Interventions that address sexual violence against girls and young women: Mapping the issues. Agenda 2015, 29, 3-12. [CrossRef]

46. Simister, J. More than a billion women face 'Gender based violence': Where are most victims? J. Family Violence 2012, 27, 607-623. [CrossRef]

47. Merry, S.E. The Seductions of Quantification: Measuring Human Rights, Gender Violence, and Sex Trafficking; University of Chicago Press: Chicago, IL, USA, 2016; ISBN 978-022-626-114-0.

48. Brackenridge, C.; Fasting, K.; Kirby, S.; Leahy, T. Protecting Children from Violence in Sport: A Review with a Focus on Industrialized Countries; UNICEF Innocenti Research Centre: Florence, Italy, 2010; ISBN 978-88-89129-96-8.

49. United Nations. Beijing Declaration and Platform for Action. 1995. Available online: https://www.un.org/ womenwatch/daw/beijing/pdf/BDPfA\%20E.pdf (accessed on 13 March 2019).

50. Galati, A.J. Onward to 2030: Sexual and reproductive health and rights in the context of the Sustainable Development Goals. Guttmacher Policy Rev. 2015, 18, 77-84.

51. Bobel, C. The Managed Body: Developing Girls and Menstrual Health in the Global South; Palgrave MacMillian: London, UK, 2019; ISBN 978-3-319-89414-0.

52. Sistersong. Reproductive Justice. 2019. Available online: https://www.sistersong.net/reproductive-justice (accessed on 28 June 2019).

53. Brackenridge, C.; Bringer, J.D.; Bishopp, D. Managing cases of abuse in sport: Child abuse review. J. Br. Assoc. Study Prev. Child Abuse Negl. 2005, 14, 259-274.

54. Fasting, K.; Brackenridge, C.; Sundgot-Borgen, J. Experiences of sexual harassment and abuse among Norwegian elite female athletes and nonathletes. Res. Q. Exerc. Sport 2003, 74, 84-97. [CrossRef]

55. Stirling, A.E.; Kerr, G.A. Defining and categorizing emotional abuse in sport. Eur. J. Sport Sci. 2008, 8, 173-181. [CrossRef]

56. Cense, M.; Brackenridge, C. Temporal and developmental risk factors for sexual harassment and abuse in sport. Eur. Phys. Educ. Rev. 2001, 7, 61-79. [CrossRef]

57. Fasting, K.; Brackenridge, C.; Walseth, K. Consequences of sexual harassment in sport for female athletes. J. Sex. Aggress. 2002, 8, 37-48. [CrossRef]

58. Fasting, K. Research on Sexual Harassment and Abuse in Sport. 2005. Available online: http://www. idrottsforum.org/articles/fasting/fasting050405.pdf (accessed on 2 June 2019).

59. Rock, K.; Valle, C.; Grabman, G. Physical inactivity among adolescents in Managua, Nicaragua: A cross-sectional study and legal analysis. J. Sport Dev. 2013, 1, 48-59.

60. Usher, L.E.; Kersetter, D. (Surfistas locales: Transnationalism and the construction of surfer identity in Nicaragua. J. Sport Soc. Issues 2015, 39, 455-479. [CrossRef]

61. Hayhurst, L.M.C. Image-ining resistance: Using postcolonial feminist participatory action research and visual research methods in sport for development and peace. Third World Themat. 2017, 2, 117-140. [CrossRef]

62. Women Win. GBV Guide. 2019. Available online: http://guides.womenwin.org/gbv (accessed on 19 February 2019).

63. Brecklin, L.R. Evaluation outcomes of self-defense training for women: A review. Aggress. Violent Behav. 2008, 13, 60-76. [CrossRef]

64. Hollander, J.A. The roots of resistance to women's self-defense. Violence Against Women 2009, 15, 574-594. [CrossRef]

65. Van Ingen, C. Spatialities of anger: Emotional geographies in a boxing program for survivors of violence. Sociol. Sport J. 2011, 28, 171-188. [CrossRef]

66. Van Ingen, C. Shape your life and embrace your aggression: a boxing project for female and trans survivors of violence. Women Sport Phys. Act. J. 2011, 20, 66-77. [CrossRef]

67. Van Ingen, C. Getting lost as a way of knowing: The art of boxing within Shape Your Life. Qual. Res. Sport Exerc. Health 2016, 8, 472-486. [CrossRef]

68. Forde, S.D. Look after yourself, or look after one another? An analysis of life skills in sport for development and peace HIV prevention curriculum. Sociol. Sport J. 2014, 31, 287-303. [CrossRef] 
69. Mwaanga, O. Sport for addressing HIV/AIDS: Explaining our convictions. Leis. Stud. Assoc. Newsl. 2010, 85, 61-67.

70. Mwaanga, O.; Banda, D. A postcolonial approach to understanding sport-based empowerment of people living with HIV/AIDS (PLWHA) in Zambia: The case of the cultural philosophy of Ubuntu. J. Disabil. Relig. 2014, 18, 173-191. [CrossRef]

71. Carney, A.; Chawansky, M. Taking sex off the sidelines: Challenging heteronormativity within 'Sport in Development'research. Int. Rev. Sociol. Sport 2016, 51, 284-298. [CrossRef]

72. Rhind, D.; Brackenridge, C.; Kay, T.; Owusu-Sekyere, F. Child protection and SDP: The post-MDG agenda for policy, practice and research. In Beyond Sport for Development and Peace: Transnational Perspectives on Theory, Policy and Practice; Hayhurst, L.M.C., Kay, T., Chawansky, M., Eds.; Routledge: London, UK, 2015; pp. $72-86$. ISBN 978-1138806672.

73. Hayhurst, L.M.C.; MacNeill, M.; Kidd, B.; Knoppers, A. Gender-based violence and Sport for Development and Peace: Questions, concerns and cautions emerging from Uganda. Women Stud. Int. Forum 2014, 47, 157-167. [CrossRef]

74. Arora-Jonnsson, S. Forty years of gender research and environmental policy: Where do we stand? Women Stud. Int. Forum 2014, 47, 295-308. [CrossRef]

75. Wonders, N.A.; Danner, M.J.E. Gendering climate change: A feminist criminological perspective. Crit. Criminol. 2015, 23, 401-416. [CrossRef]

76. Sasser, J. Sexual stewardship: environment, development, and the gendered politics of population. In The Routledge Handbook of Gender and Environment; MacGregor, S., Ed.; Routledge: London, UK, 2017; pp. 345-357. ISBN 0-415-70774-9.345-357.

77. Murphy, M. The Economization of Life; Duke University Press: Durham, NC, USA, 2017; ISBN 978-0-8223-6345-3.

78. Bradshaw, S. Women, Poverty and Disasters: Exploring the Links through Hurricane Mitch in Nicaragua. In The International Handbook of Gender and Poverty: Concepts, Research, Policy; Chant, S., Ed.; Edward Elgar Publishing: London, UK, 2010; pp. 516-522.

79. Resurrección, B.P. Gender and the environment in the Global South: From 'women, environment and development' to feminist political ecology. In The Routledge Handbook of Gender and Environment; MacGregor, S., Ed.; Routledge: London, UK, 2017; pp. 71-85. ISBN 0-415-70774-9.345-357.

80. Agarwal, B. The gender and environment debate: Lessons from India. Fem. Stud. 1992, 18, 119-158. [CrossRef]

81. MacGregor, S. Gender and environment: an introduction. In The Routledge Handbook of Gender and Environment; MacGregor, S., Ed.; Routledge: London, UK, 2017; pp. 1-25. ISBN 0-415-70774-9.345-357.

82. Cannella, G.S.; Manuelito, K.D. Feminisms from unthought locations: Indigenous worldviews, marginalized feminisms, and revisioning anticolonial social science. In Handbook of Critical and Indigenous Methodologies; Denzin, N., Lincoln, Y., Smith, L.T., Eds.; Sage: London, UK, 2008; pp. 45-59.

83. Thompson, C.; MacGregor, S. The Death of Nature: foundations of ecological feminist thought. In The Routledge Handbook of Gender and Environment; MacGregor, S., Ed.; Routledge: London, UK, 2017; pp. 43-54. ISBN 0-415-70774-9.345-357.

84. MacGregor, S. A stranger silence still: The need for feminist social research on climate change'. Sociol. Rev. 2018, 57, 124-140. [CrossRef]

85. Coole, D.; Frost, S. Introducing the new materialisms. In New Materialisms: Ontology, Agency and Politics; Coole, D., Frost, S., Eds.; Duke University Press: Durham, UK, 2010; pp. 1-43.

86. Latour, B. Reassembling the Social: An Introduction to Actor-Network-Theory; Oxford University Press: Oxford, UK, 2005.

87. Harding, S. Sciences from Below: Feminisms, Postcolonialities, and Modernities; Duke University Press: Durham, UK, 2008.

88. Harding, S. Introduction. beyond postcolonial theory: Two undertheorized perspectives on science and technology. In The Postcolonial Science and Technology Studies Reader; Harding, S., Ed.; Duke University Press: Durham, UK, 2011; pp. 1-33.

89. Alaimo, S.; Hekman, S. Introduction: Emerging models of materiality in feminist theory. In Material Feminisms; Alaimo, S., Hekman, S., Eds.; Indiana University Press: Bloomington, IN, USA, 2008; pp. 1-23.

90. Darnell, S.C.; Giulianotti, R.; Howe, P.D.; Collison, H. Re-assembling sport for development and peace through actor network theory: Insights from Kingston, Jamaica. Sociol. Sport J. 2018, 35, 89-97. [CrossRef] 
91. Fatimah, Y.A.; Arora, S. Nonhumans in the practice of development: Material agency and friction in a small-scale energy program in Indonesia. Geoforum 2016, 70, 25-34. [CrossRef]

92. Li, T. The Will to Improve: Governmentality, Development, and the Practice of Politics; Duke University Press: Durham, UK, 2007.

93. Disney, L. Women's Activism and Feminist Agency in Mozambique and Nicaragua; Temple University Press: Philadelphia, PA, USA, 2008.

94. Lancaster, R.N. Skin color, race, and racism in Nicaragua. Ethnology 1991, 30, 339-353. [CrossRef]

95. Nouvet, E. Extraordinary aid and its shadow: The significance of gratitude in Nicaraguan humanitarian healthcare. Critique Anthropol. 2016, 36, 1-20. [CrossRef]

96. Eckstein, D.; Hutfils, M.-L.; Winges, M. Global Climate Risk Index 2019: Who Suffers Most from Extreme Weather Events? Weather-Related Loss Events in 2017 and 1998 to 2017. Available online: https://germanwatch.org/sites/germanwatch.org/files/Global\%20Climate\%20Risk\%20Index\%202019_ 2.pdf (accessed on 12 June 2019).

97. USAID. Nicaragua Climate Change Risk Profile. 2017. Available online: https://www.climatelinks.org/ sites/default/files/asset/document/2017_USAID_Nicaragua\%20Climate\%20Change\%20Risk\%20Profile.pdf (accessed on 19 June 2019).

98. Pena, N.; Maiques, M.; Castillo, G.E. Using rights-based and gender-analysis arguments for land rights for women: Some initial reflections from Nicaragua. Gender Dev. 2008, 16, 55-71. [CrossRef]

99. Cobo del Arco, T. Políticas de g’Enerodurante el Liberalismo: Nicaragua, 1893-1909; UCA: Managua, Nicaragua, 2000.

100. Collinson, H. Women and Revolution in Nicaragua; Zed Press: London, UK, 1990.

101. Human Rights Watch. Country Chapters-Nicaragua. 2019. Available online: https://www.hrw.org/worldreport/2019/country-chapters/nicaragua\#9b8180 (accessed on 15 June 2019).

102. Jubb, N. Love, family values and reconciliation for all, but what about rights, justice and citizenship for women? The FSLN, the women's movement, and violence against women. Bull. Latin Am. Res. 2014, 33, 289-304. [CrossRef]

103. Radcliffe, S. Gender and postcolonialism. In Routledge Handbook of Gender and Development; Coles, A., Gray, L., Momsen, J., Eds.; Routledge: London, UK, 2015; pp. 35-47. ISBN 978-0415829083.

104. Mitchell, C.; de Lange, N.; Molestsane, R. Participatory Visual Methodologies: Social Change, Community and Policy; Sage Publications: London, UK, 2017; ISBN 978-1-4739-4730-6.

105. Reid, C.; Frisby, W. Continuing the journey: Articulating dimensions of Feminist Participatory Action Research (FPAR). In Sage Handbook of Action Research; Reason, P., Bradbury, H., Eds.; Sage: London, UK, 2008; ISBN 978-1446271148.

106. Wang, C.; Burris, M.A.; Ping, X.Y. Chinese village women as visual anthropologists: A participatory approach to reaching policymakers. Soc. Sci. Med. 1996, 42, 1391-1400. [CrossRef]

107. Castleden, H.; Garvin, T.; First Nation, H.; Huu-ay-aht First Nation. Modifying photovoice for community-based participatory indigenous research. Soc. Sci. Med. 2008, 66, 1393-1405. [CrossRef]

108. Barker, J.; Smith, F. What's in focus? A critical discussion of photography, children and young people. Int. J. Soc. Res. Methodol. 2012, 15, 91-103. [CrossRef]

109. De Lisio, A. York University, Toronto, Canada. Personal communication (email), 2019.

110. Arora-Jonsson, S. Virtue and vulnerability: Discourses on women, gender and climate change. Global Environ. Chang. 2011, 21, 744-751. [CrossRef]

111. Ciplet, D.; Roberts, J.T. Splintering south: Ecologically unequal exchange theory in a fragmented global climate. In Ecologically Unequal Exchange: Environmental Injustice in Comparative and Historical Perspective; Frey, R.S., Gellert, P.K., Dahms, H.F., Eds.; Springer Nature: Cham, Switzerland, 2018; pp. 273-305, ISBN 978-331-989-739-4.

112. McSweeney, M.J.; Millington, B.; Hayhurst, L.M.C.; Wilson, B.; Ardizzi, M.; Otte, J. "The actual use of them is complex": Actor-network theory, the bicycle, and other non-human actors in international development. (Under review). Int. Rev. Soc. Sport.

113. Slocum, R. Polar bears and energy-efficient lightbulbs: Strategies to bring climate change home. Environ. Plan. D Soc. Space 2004, 22, 413-438. [CrossRef] 
114. Gubrium, A.C.; Hill, A.L.; Flicker, S. A situated practice of ethics for participatory visual and digital methods in public health research and practice: A focus on digital storytelling. Am. J. Public Health 2014, 104, 1606-1614. [CrossRef]

115. Ahmed, S. Living a Feminist Life. Duke University Press: Durham, NC, USA, 2017; ISBN 978-0822363194.

(C) 2019 by the authors. Licensee MDPI, Basel, Switzerland. This article is an open access article distributed under the terms and conditions of the Creative Commons Attribution (CC BY) license (http://creativecommons.org/licenses/by/4.0/). 